\title{
Behavioral flexibility and problem solving in an invasive bird
}

Corina J Logan

Behavioral flexibility is considered an important trait for adapting to environmental change, but it is unclear what it is, how it works, and whether it is a problem solving ability. I investigated behavioral flexibility and problem solving experimentally in greattailed grackles, an invasive bird species and thus a likely candidate for possessing behavioral flexibility. Grackles demonstrated behavioral flexibility in two contexts, the Aesop's Fable paradigm and a color association test. Contrary to predictions, behavioral flexibility did not correlate across contexts. Four out of 6 grackles exhibited efficient problem solving abilities, but problem solving efficiency did not appear to be directly linked with behavioral flexibility. Problem solving speed also did not significantly correlate with reversal learning scores, indicating that faster learners were not the most flexible. These results reveal how little we know about behavioral flexibility, and provide an immense opportunity for future research to explore how individuals and species can use behavior to react to changing environments. 


\title{
Behavioral flexibility and problem solving in an invasive bird
}

\author{
Corina J. Logan*
}

SAGE Center for the Study of the Mind, University of California Santa Barbara, Santa Barbara, CA 93103 USA

*Current address: Department of Zoology, University of Cambridge, Cambridge CB2 3EJ

United Kingdom

E-mail: cl417@cam.ac.uk, phone: +44 7868357 294, fax: +44 1223336676

\section{BACKGROUND}

Behavioral flexibility, defined here as the ability to change preferences when circumstances change based on learning from previous experience or using causal knowledge, is frequently implicated as a key factor involved in problem solving success and adapting behavior to changing environments (e.g., Lefebvre et al. 1997, Griffin \& Guez 2014, Buckner 2015, Chow et al. 2016). Those individuals or species that are more behaviorally flexible are predicted to learn faster and more efficiently, and rely on more learning strategies to solve problems (Griffin \& Guez 2014). Testing behavioral flexibility experimentally requires individuals to change their behavior in response to changes in the task.

A common way to experimentally test behavioral flexibility uses a reversal learning paradigm where individuals first learn to prefer a particular option, and then, once proficient, the reward contingencies are altered such that previously correct choices are now unsuccessful, therefore the individual must learn to change its preference (e.g., Bond et al. 2007, Tebbich et al. 2010, Ghahremani et al. 2010, Buckner 2013). The few investigations that have examined the relationship between behavioral flexibility and problem solving abilities produced mixed results. 
24 Two studies investigating behavioral flexibility and problem solving speed found that faster

25 learners were slower to reverse their preferences (invasive Indian mynas: Griffin et al. 2013,

26 threatened Florida scrub-jays: Bebus et al. 2016). Another study found no correlation between

27 reversal learning speed and problem solving speed or ability (color and shape discrimination, 28 spatial memory, and motor skills; spotted bowerbirds: Isden et al. 2013). Reversal learning speed 29 is thought to positively correlate with inhibition: When the task changes subjects must inhibit the 30 previously learned behavior to be able to learn the new behavior (Manrique et al. 2013, Griffin \& 31 Guez 2014, Liu et al. 2016). However, this idea is challenged by an experiment in rats that were 32 genetically modified to increase inhibition (Homberg et al. 2007). Knock out rats with improved inhibition showed no difference in their reversal learning speed from non-modified rats 34 (Homberg et al. 2007). This suggests that behavioral flexibility may rely more on individuals continuing to sample their environment rather than simply inhibiting a response when a behavior is no longer rewarded. This variety of contrasting results indicates how little is known about behavioral flexibility in terms of how it relates to problem solving abilities and cognition. aspects are measurable in problem solving tasks while other aspects are measurable in other contexts, therefore individuals might exhibit flexibility in some contexts but not others. Behavioral flexibility is usually studied in relation to problem solving speed (Griffin et al. 2013, Bebus et al. 2016), not problem solving success, and, while behavioral flexibility is also tested in non-reversal learning paradigms (e.g., multi-access box: Auersperg et al. 2011, Manrique et al. 44 2013; episodic-like memory and future planning: Clayton \& Dickinson 1998, Dally et al. 2006, Raby et al. 2007), it is generally tested in only one context per study. Therefore, our understanding of the mechanisms underlying behavioral flexibility is lacking. 
To begin to address these gaps, I investigated behavioral flexibility in one of the most invasive species in North America, the great-tailed grackle (Quiscalus mexicanus, family

49 Icteridae, hereafter referred to as grackles; Peer 2011). Species that rapidly adapt to novel 50 environments are presumed to require the ability to behaviorally respond to changing 51 circumstances within the course of their lifetime (Sol \& Lefebvre 2000, Sol et al. 2002, Sol et al. 52 2005, Sol et al. 2007), thus many invasive species are likely candidates for possessing behavioral 53 flexibility. I investigated whether grackles are behaviorally flexible and efficient problem solvers, whether they vary in behavioral flexibility across contexts, whether flexibility correlates with problem solving ability and speed, and whether individuals that are more flexible use more 56 learning strategies.

I tested behavioral flexibility in two contexts by measuring preferences (due to learning, attending to function, or previous experience) and then requiring individuals to change preferences after modifying the task. A color association task (context 1) involved a gold tube and a silver tube placed on the table at the same time and with one of the tubes containing hidden food. Individuals learned to associate food with first the gold tube (learning speed; Experiment 1) and then the silver tube (a modified version of reversal learning in that there was only 1 reversal; Experiment 2). I used this task to compare the speed with which grackles learn and reverse preferences compared with other species, and to examine which learning strategies grackles use to become proficient. Economics theory calls this type of problem a contextual, binary multi-armed bandit and predicts two different learning strategies as solutions to the problem (McInerney 2010). These learning strategies involve a trade off between an exploration phase and an exploitation phase. The pattern of the trade off indicates which learning strategy was used. For example, a short exploration phase before switching almost exclusively to the 
70 exploitation phase (marked by significantly more correct choices) indicates one learning strategy,

71 whereas a long exploration phase before eventually choosing significantly more correct choices

72 (exploitation phase) indicates a different learning strategy.

73 The Aesop's Fable paradigm (context 2) examines problem solving ability and involves

74 food floating in a partially filled water tube, which is solved by inserting objects into the tube to

75 raise the water level and bring the food within reach. It has been used to explore the cognitive 76 abilities underlying problem solving in rooks (Bird \& Emery 2009), Eurasian jays (Cheke et al.

77 2011), humans (Cheke et al. 2012), New Caledonian crows (Taylor et al. 2011, Jelbert et al. 78 2014, Logan et al. 2014), and Western scrub-jays (Logan et al. 2016). While great-tailed grackles

79 are not reported to use tools (grackles are not listed in Lefebvre et al. 2002), non-tool using 80 species have successfully participated in the Aesop's Fable tests (rooks: Bird \& Emery 2009, 81 Eurasian jays: Cheke et al. 2011, and Western scrub-jays: Logan et al. 2016) as well as other 82 tool-using tests (e.g., the trap tube; rooks: Seed et al. 2006, Tebbich et al. 2007), therefore I 83 expect grackles to be capable of performing these experiments. I compared grackle problem 84 solving performance with previously tested species to determine whether grackles are efficient 85 problem solvers. I modified the standard Aesop's Fable experiments to test behavioral flexibility 86 by assessing whether they prefer to drop the more functional heavy objects in a Heavy vs. Light 87 experiment, and whether they change these preferences in a follow up experiment where the 88 heavy objects become non-functional (Heavy vs. Light Magic).

90 GENERAL METHODS

91 Ethics 
92 This research was carried out in accordance with permits from the U.S. Fish and Wildife Service

93 (scientific collecting permit number MB76700A), California Department of Fish and Wildlife

94 (scientific collecting permit number SC-12306), U.S. Geological Survey Bird Banding

95 Laboratory (federal bird banding permit number 23872), and the Institutional Animal Care and

96 Use Committee at the University of California Santa Barbara (IACUC protocol numbers 860 and $97860.1)$.

99 Subjects and Study Site

100 Eight wild adult great-tailed grackles (4 females and 4 males) were caught using a walk-in baited 101 trap measuring $0.61 \mathrm{~m}$ high by $0.61 \mathrm{~m}$ wide by $1.22 \mathrm{~m}$ long (design from Overington et al. 2011). 102 Birds were caught (and tested) in two batches: batch 1 at the Andree Clark Bird Refuge (4 birds 103 [Tequila, Margarita, Cerveza, and Michelada] in September 2014, released in December) and 104 batch 2 at East Beach Park (4 birds [Refresco, Horchata, Batido, and Jugo] in January 2015, 105 released in March) in Santa Barbara, California. They were housed individually in aviaries 106 measuring $183 \mathrm{~cm}$ high by $119 \mathrm{~cm}$ wide by $236 \mathrm{~cm}$ long at the University of California Santa 107 Barbara for 2-3 months while participating in the experiments in this study. Grackles were given 108 water ad libitum and unrestricted amounts of food (Mazuri Small Bird Food) for at least 20 hrs 109 per day, with their main diet being removed for up to $4 \mathrm{hrs}$ on testing days while they 110 participated in experiments and received peanuts or bread when successful. Grackles were aged

111 by plumage and eye color and sexed by plumage and weight following Pyle (2001). Biometrics,

112 blood, and feathers were collected at the beginning and end of their time in the aviary. Their

113 weights were measured at least once per month, first at the time of trapping using a balancing 
114 scale, and subsequently by placing a kitchen scale covered with food in their aviary and

115 recording their weight when they jumped onto the scale to eat.

116

\section{Experimental Set Up}

118 Apparatuses were placed on top of rolling tables $(60 \mathrm{~cm}$ wide by $39 \mathrm{~cm}$ long) and rolled into each

119 individual's aviary for testing sessions, which lasted up to approximately $20 \mathrm{~min}$. If habituation to

120 an apparatus was needed, as indicated by a bird's unwillingness to immediately approach and eat

121 from it (this was the case for most birds with the stone dropping training apparatus), it was

122 placed in their aviary overnight and they were fed from it. If an apparatus had parts that would

123 allow a bird to learn how the task worked, these parts were taped over to prevent learning. If a

124 grackle approached an apparatus and ate from it without hesitating, it was considered habituated.

125 If re-habituation was needed, as indicated by an unwillingness to approach the apparatus after the

126 training or experiment began, the habituation process was repeated. Color tubes were baited with

127 peanut pieces and/or bread. Water tubes were baited with $1 / 16$ of a peanut attached to a small

128 piece of cork with a tie wrap for buoyancy (hereafter referred to as a peanut float). The area

129 around the top of the water tube (the standing platform) was also sometimes baited with smaller

130 peanut pieces and bread crumbs, and more peanut floats could be added to the inside of the water

131 tube to encourage the bird to interact with the task. If more than one peanut float was in the tube,

132 the bird was given the opportunity, after retrieving the first peanut float, to insert more objects

133 into the tube to retrieve the other peanut floats. If a bird started to lose motivation (e.g., refuse to

134 come to the table or interact with the apparatus) for participating in a task because they were

135 unsuccessful (as in Heavy vs. Light Magic), I baited the standing platform between trials to

136 reward their participation and keep them interested in finishing the experiment. A trial was 
137 terminated when the bird solved the task or did not interact with the apparatus for at least 1 min.

138 All water tube experiments (3-6) consisted of 20 trials per bird and were recorded with a Nikon

139 D5100 camera on a tripod placed inside the aviary. Experiments were given in the following

140 order: 1, 3, 4, 5, 6, 2, which was the same for all birds (except Tequila who began, but did not

141 complete, a sand vs. water experiment between Experiments 1 and 3). Grackles took 1-7 days to

142 complete an experiment, which could have spanned the course of up to 19 days. Birds were

143 tested with the experimenter just outside the aviary door and in full sight of the grackle. Grackles

144 are already habituated to humans because they forage in an urban setting, often coming within a

145 meter of the nearest humans. They quickly habituated to the testing set up and their first 5 days

146 in the aviary were spent habituating them to a human presence just outside their aviary door.

\section{Experimenters}

149 My research assistant, Luisa Bergeron, and I conducted Experiments 1-2; I conducted 150 Experiments 3-6; and my assistants (Luisa Bergeron, Alexis Breen, Michelle Gertsvolf, Christin 151 Palmstrom, and Linnea Palmstrom) and I conducted the stone dropping training.

\section{Statistical Analyses}

154 Color Association Tests

155 Two analyses were performed on the color association data (Experiments 1 and 2). First, a bird 156 was considered to pass this test if it chose correctly at least 17 out of the most recent 20 trials

157 (with a minimum of 8 or 9 correct choices out of 10 on the two most recent sets of 10; binomial 158 test: $\mathrm{p}=0.003$ for $17 / 20$ ). Once the bird reached proficiency using this analysis, their individual

159 learning strategy was identified using a contextual, binary multi-armed bandit (see McInerney 
1602010 for a review). It was contextual in that the subject was allowed to make only one choice per

161 trial, and binary because there were two options on the table, one containing a reward and the

162 other containing no reward. I categorized grackle learning strategies by matching them to the two

163 known approximate strategies of the contextual, binary multi-armed bandit: epsilon-first and 164 epsilon-decreasing (McInerney 2010). The following equations refer to the different phases

165 involved in each strategy:

166

168

169

170

171

172

173

174

175

176

177

178

179

180

181

182

Equation 1 (exploration phase): $\in \mathrm{N}$

$$
\text { Equation } 2 \text { (exploitation phase): (1-€) } \mathrm{N}
$$

$\mathrm{N}$ is the number of trials given, and epsilon, $\epsilon$, represents the subject's uncertainty about the location of the reward, starting at complete uncertainty $(\epsilon=1)$ at the beginning of the experiment and decreasing rapidly as individuals gain experience with the task (exploration phase where the rewarded color is chosen below or at chance levels) and switch to the exploitative phase (the rewarded color is chosen significantly above chance levels). Because the grackles needed to learn the rules of the task, they necessarily had an exploration phase. The epsilon-first strategy involves an exploration phase followed by an entirely exploitative phase. The optimal strategy overall would be to explore one color in the first trial and the other color in the second trial, and then switch to an exploitative strategy (choose the rewarded color significantly above chance levels). In this case there would be no pattern in the choices in the exploration phase because it would consist of sampling each color only once. In the epsilon-decreasing strategy, birds would start by making some incorrect choices and then increase their choice of gold gradually as their uncertainty decreases until they choose the rewarded color significantly above chance levels. In this case, a linear pattern emerges during the exploration phase.

To determine whether faster learners are also more flexible, I used a Spearman's rank 
183 correlation test to examine whether learning speed (number of trials to learn a preference)

184 correlated with reversal learning scores (number of trials to reverse a preference minus the

185 number of trials to learn the preference) in the color association test.

187 Aesop's Fable tests

188 To make the water tube experimental results comparable with previous studies, I used two-tailed

189 binomial tests to determine whether each grackle chose particular objects or tubes at random

190 chance (null hypothesis: $\mathrm{p} \geq 0.05$ ) or significantly above chance (alternative hypothesis: $\mathrm{p}<0.05$ ).

191 The Bonferroni-Holm correction was applied to p-values within each experiment to correct for

192 an increase in false positive results that could arise from conducting multiple tests on the same

193 dataset.

194 Generalized linear mixed models (GLMMs) were used to determine whether birds

195 preferred particular objects or tubes (response variable: correct/more correct choice or

196 incorrect/less correct choice) in a water tube experiment and whether the trial number or bird

197 influenced choices (explanatory variables: experiment, trial number, bird), and to control for the

198 non-independence of multiple choices per trial (random factor: choice number). I used minimal

199 belief priors $(\mathrm{V}=1, \mathrm{nu}=0)$ and fixed the variance component to one $(\mathrm{fix}=1)$ because the

200 measurement error variance was known, as is standard when choices are binary (Hadfield 2010).

201 I ensured that the Markov chain for this test model converged by manipulating the number of

202 iterations (nitt=150000 for the null model, nitt=600000 for the test model), the number of

203 iterations that must occur before samples are stored (burnin=30000), and the intervals the

204 Markov chain stores (thin=300) until successive samples were independent as indicated by low

$205(<0.1)$ correlations (autocorr function, MCMCglmm package: Hadfield 2014a,b) and there were 
206 no trends when visually inspecting the time series of the Markov chain (function:

207 plot(testmodel\$Sol); Hadfield 2014a,b). I compared this test model to a null model where I

208 removed all explanatory factors and set it to 1.

209 I determined whether the test model was likely given the data, relative to the null model,

210 by using Akaike weights (range: 0-1, all model weights sum to 1; Akaike 1981; Weights

211 function, MuMIn package: Bates et al. 2011). The Akaike weight indicates the "relative

212 likelihood of the model given the data" (Burnham and Anderson 2002, p. xxiii) and models with

213 Akaike weights greater than 0.89 are considered reliable models because they are highly likely

214 given the data (Burnham and Anderson 2002). The test model was highly likely given the data

215 (Akaike weight=1.00) and the null model was not (Akaike weight=3.4e-30), therefore the test

216 model was highly likely given the data. To investigate the potential effects of season or order of

217 testing, I conducted a GLMM to determine whether the batch to which the bird belonged

218 (explanatory variable: batch=1 or 2) influenced their test performance (response variable: correct

219 or incorrect choice) while controlling for the non-independence of multiple choices per trial

220 (random factor: choice number). The null model was highly likely given the data (Akaike

221 weight $=0.94$ ), while the batch model was not (Akaike weight $=0.06$ ), indicating that batch did not

222 influence test performance. GLMMs were carried out in R v3.2.1 (R Core Team 2016) using the

223 MCMCglmm function (MCMCglmm package, Hadfield 2014a) with a binomial distribution

224 (called categorical in MCMCglmm) and logit link.

Cross-Context Analysis

227 To determine whether those grackles that were more behaviorally flexible in the water tube

228 context (yes or no) were also more behaviorally flexible in the color association context (the 
229 number of trials to meet criterion in experiment 2 minus the number of trials to meet criterion in

230 experiment 1), I used a Spearman's rank correlation test. Margarita and Cerveza were included,

231 even though their attraction to the magnet in Experiment 4 biased their results, to increase the

232 sample size of individuals that participated in both contexts to 5 .

233

234 Data Availability

235 The data are available at the KNB Data Repository:

236 https://knb.ecoinformatics.org/\#view/corina_logan.15.6 (Logan 2015).

237

238 Video

239 Watch video clips showing examples of each experiment at: https://youtu.be/GhR6fGG1yc4.

241 CONTEXT 1: COLOR ASSOCIATION TESTS

242 Experiment 1: Color Association Test (learning speed)

243 Experiment 1: Methods

244 To assess how many trials it takes a grackle to form an association between food and color, they

245 were given a gold and a silver tube with food (peanut pieces or bread) always hidden in the gold

246 tube (Logan et al. 2014 \& 2016). Grackles were first trained on a blue tube where they learned to

247 search for hidden food. Each color tube set up consisted of a PVC tube (outer diameter 26mm,

248 inner diameter $19 \mathrm{~mm}$ ) mounted on two pieces of plywood glued together at a right angle (whole

249 apparatus measuring $50 \mathrm{~mm}$ wide by $50 \mathrm{~mm}$ tall by $67 \mathrm{~mm}$ deep). Each tube was placed at

250 opposite ends of a table with the tube openings facing the side walls so the bird could not see

251 which tube contained the food. Tubes were pseudorandomized for side and the left tube was 
252 always placed first, followed by the right to avoid behavioral cueing. Pseudorandomization

253 consisted of alternating location for the first two trials of a session and then keeping the same

254 color on the same side for at most 2 consecutive trials thereafter. Each trial consisted of placing

255 the tubes on the table, and then the bird had the opportunity to choose one tube by looking into it

256 (and eating from it if it chose the gold tube). Once the bird chose, the trial ended by removing the

257 tubes.

258

259 Experiment 1: Results

260 All grackles learned to associate the gold tube with a food reward by reaching criterion (at least

261 17/20 correct trials) in 20-40 trials (Table 1). Using the binary multi-armed bandit analysis to

262 assess which learning strategies birds used, Refresco used the epsilon-first strategy because he

263 first explored (i.e., made unsuccessful and/or successful choices) and then exploited (i.e., was

264 successful) every trial thereafter: He explored in his first trial (he failed by choosing silver) and

265 then always chose gold after that (Figure 1). The rest of the grackles used the epsilon-decreasing

266 strategy by exploring more at the beginning and gradually increasing their success until they

267 performed above chance levels by the end of the experiment (Figure 1). Horchata and Jugo had

268 exceptions to this strategy: Horchata started a second exploration phase at the end of her

269 experiment, and Jugo's pattern of exploration did not linearly increase in his first several trials

270 (though it did thereafter). In the first part of Jugo's experiment, he did not appear to follow any

271 particular rules during his learning phase such as 'always choose the left side' or 'always

272 alternate sides', therefore it is unknown how this part of his exploration phase should be

273 classified according to economics theory. 
275

276 Grackles were fast to learn an initial preference in the color association task (average 31 trials).

277 Their performance is similar to Western scrub-jays (Logan et al. 2016), 3 species of Darwin's

278 finches (Tebbich et al. 2010), and pigeons (Lissek et al. 2002) who learned in an average of 279 between 40-56 trials using a similar experimental design and passing criterion. These species are 280 faster than Pinyon jays, Clark's nutcrackers, a different group of Western scrub-jays (Bond et al. 281 2007), and Indian mynas (Griffin et al. 2013) who learned on average between 122-280 trials and 282 also had a similar passing criterion and experimental design. The Indian myna's design was 283 different, however they are included for comparison because they are one of the only other 284 species that has been tested in a similar behavioral flexibility-problem solving context. If 285 grackles trade off learning speed for inhibition (implicated in behavioral flexibility; Manrique et 286 287 288 289 290 291

\section{Experiment 2: Color Association Reversal (learning speed)}

293 Experiment 2: Methods

294 The methods were the same as in the color association test (Experiment 1), except the food was 295 always placed in the silver tube rather than the gold tube, thus forcing the bird to reverse their 296 preference to consistently obtain the food. Because many other experiments (3-6) occurred 297 between Experiments 1 and 2, I first checked whether the grackles remembered Experiment 1 
298 before moving them to Experiment 2. If they were successful in 9 or 10 out of their first 10 trials,

299 indicating that they remembered that the food was always in the gold tube, then they moved onto

300 reversal learning with the food always in the silver tube. If they were not successful in their first

30110 trials, then they were given a refresher on Experiment 1 until they re-passed the original

302 criterion before moving onto reversal learning.

303

304 Experiment 2: Results

305 For their Experiment 1 refresher, Margarita, Cerveza, Michelada, and Jugo remembered that

306 food was always in the gold tube because they passed in their first 10 trials (Table 1, Figure 2).

307 Tequila, Horchata, Refresco, and Batido needed to re-achieve proficiency on Experiment 1,

308 requiring 30-80 trials before moving onto Experiment 2 (Table 1). Their re-learning patterns

309 followed the epsilon-decreasing strategy that all birds used before, except for Refresco who used

310 the epsilon-first strategy the first time and switched to the epsilon-decreasing strategy for the

311 refresher (Figure 2).

312 Most grackles reversed their color association, indicating they were behaviorally flexible.

313 Seven out of 8 grackles met the reversal learning success criterion (17 correct choices out of the

314 most recent 20 trials) in 70-130 trials (Table 1), but Batido stopped participating before reaching

315 criterion (Figure 3). All birds used the epsilon-decreasing strategy, but they were slower to learn

316 to reverse their previously learned preference than they were to initially learn the preference, and

317 many continued to explore throughout the experiment (Figure 3).

318 Faster learners were not more flexible. In the color association test, learning speed

319 (number of trials to learn a preference) did not significantly correlate with reversal learning 
320 scores (number of trials to reverse a preference minus the number of trials to learn the

321 preference; Spearman's rank correlation test: $S=84.14, p=0.25$, rho=-0.50, $n=7$ ).

322

323 Experiment 2: Discussion

324 Grackles demonstrated behavioral flexibility in the color association task by quickly reversing

325 their initially learned preference (average 91 trials). Their performance was similar to 3 species

326 of Darwin's finches who reversed in an average of 76-95 trials (Tebbich et al. 2010). Darwin's

327 finches and grackles reversed more quickly than pigeons (Lissek et al. 2002), Pinyon jays,

328 Clark's nutcrackers, Western scrub-jays (Bond et al. 2007), and Indian mynas (Griffin et al.

329 2013) who learned on average between 142-380 trials.

330 Faster learners were not less flexible (e.g., slower to reverse a preference), which is 331 predicted if learning speed trades off with inhibition or continuing to sample the environment,

332 and was found in Indian mynas and Florida scrub-jays (Manrique et al. 2013, Griffin et al. 2013,

333 Griffin \& Guez 2014, Bebus et al. 2016, Liu et al. 2016). There was no correlation between

334 grackle learning speed and behavioral flexibility, similar to results found in spotted bowerbirds

335 that were tested in the wild using a different experimental design and passing criterion (6

336 consecutive correct choices before trying an incorrect choice in 2 consecutive sessions; Isden et

337 al. 2013). Regardless of methodological differences, such unpredictable variation in behavioral

338 flexibility across species suggests that the underlying mechanisms are poorly understood and 339 require further investigation.

341 CONTEXT 2: AESOP'S FABLE TESTS

342 Context 2: General Methods and Results 


\section{Spontaneous Stone Dropping}

344 Methods: Birds were given two sequential $5 \mathrm{~min}$ trials with the stone dropping training

345 apparatus and two stones to see whether they would spontaneously drop stones down tubes. The

346 stone dropping training apparatus was a clear acrylic box with a tube on top. The box contained

347 out of reach food on top of a platform that was obtainable by dropping a stone into the top of the

348 tube, which, when contacting the platform, forced the magnet holding it up to release the

349 platform (design as in Bird and Emery 2009 with the following tube dimensions: 90mm tall, 350 outer diameter $=50 \mathrm{~mm}$, inner diameter $=37$ or $44 \mathrm{~mm})$. The food then fell from the platform to the

351 table. At the end of the first 5 min trial, the stones were moved to different locations on the table

352 and on the wooden blocks. The blocks made it easier to access the top of the tube.

353 Results: No grackle spontaneously dropped stones down the tube of the platform 354 apparatus, indicating that this was not a behavior that was easily innovated. Therefore, they all 355 underwent stone dropping training to allow them to participate in experiments 3-6.

\section{Stone Dropping Training}

358 Methods: Those birds that did not spontaneously drop stones down the tube on the stone

359 dropping training apparatus were trained to push or drop stones down tubes using this same

360 apparatus (Figure 4). Birds were given two stones and went from accidentally dropping stones

361 down the tube as they pulled at food under the stones, which were balanced on the edge of the

362 tube opening, to pushing or dropping stones into the tube from anywhere near the apparatus.

363 Once the bird proficiently pushed or dropped stones into the apparatus 30 times, they moved on

364 to obtain their reachable distance on a water tube. 

tube opening from anywhere on the standing platform at the top of the apparatus. Not all motions

367 had to be in the direction of the tube opening because some grackles preferred to move the stone 368 to a particular location on the ramp (which may initially be in the opposite direction from the 369 tube) and push or drop it in from there, or push the stone in shorter, angular strokes. It was 370 permissible for a bird to throw one of the stones off the side of the apparatus (which occurred 371 sporadically in training and experiments) as long as they proficiently put the other stone in the 372 tube. the stone from the table and putting it into the tube without a ramp (Figure 4). The modification was necessary because grackles seem to form associations between the stones and the top of the tube, the stones and the table where the food comes out, and the stones falling in one direction only: down. When I placed the stones below the level of the top of the tube to try to train them to pick the stones up and put them in the top of the tube, the grackles took the stones and dropped them off the side of the apparatus or table, often placing them on the table and then looking at where the platform should have fallen open. Placing the standing platform at the tops of the water tubes for the experiments was implemented to mitigate this limitation. Once this change 383 was made, it was no longer necessary to train the grackles to pick up and drop the stones because 384 pushing them into the tube sufficed and required less training.

Similar to Western scrub-jays (Logan et al. 2016), the grackles inserted objects while standing at the top of the tube rather than standing on the ground. The different standing position should not influence their perception of the objects as they were inserted into the tube because 
388 their heads were always over the top of the tube at the time of insertion, regardless of where they

389 were standing.

$390 \quad$ Results: Most grackles learned to push stones into a tube on the platform apparatus in

391 135-362 trials (Table 2), however Michelada showed a neophobic reaction (refused to approach

392 and interact with the apparatus even after repeated re-habituation attempts) to the stone falling

393 down the tube and did not habituate to this event, and Jugo learned too slowly to become

394 proficient by the time he needed to be released. Therefore, Michelada and Jugo were excluded

395 from the stone dropping experiments.

\section{Reachable Distance}

398 To determine how high to set the water levels in the Aesop's Fable experiments, a bird's 399 reachable distance was obtained. Food was placed on cotton inside a resealable plastic bag, 400 which was stuffed inside a standard water tube (a clear acrylic tube [170mm tall, outer 401 diameter $=51 \mathrm{~mm}$, inner diameter $=38 \mathrm{~mm}]$ super glued to a clear acrylic base $[300 \times 300 \times 3 \mathrm{~mm}]$ ) to 402 obtain the reachable distance without giving the bird experience with water. The food was first 403 placed within reach and then lowered into the tube in $1 \mathrm{~cm}$ increments until the bird could not 404 reach it. The lowest height the bird could still reach was considered its reachable distance and 405 water levels in subsequent experiments were set to allow the desired number of objects to bring 406 the food within reach.

407

\section{An Additional Experiment that Only Tequila Began: Water vs. Sand}

409 Methods: To determine whether grackles can discriminate between functional and non410 functional substrates, two standard water tubes were placed on the table: one partially filled with 
411 water (functional) and the other partially filled with sand (non-functional) to equal levels

412 (pseudorandomized for side; similar to Jelbert et al. 2014, Logan et al. 2014, Logan et al. 2016).

413 Before the experiment began, birds were habituated to the water and sand tubes for 10 trials by

414 taping over the openings at the top and placing food (peanut pieces) on the tops and at the bases

415 of each tube (there was no food inside the tubes). A trial continued until the bird ate all four food

416 pieces. The first tube from which food was taken was recorded and used as an indicator of a

417 potential preference. Preferences were discouraged by placing relatively more bait on the non-

418 preferred tube in the next trial. During the 20-trial experiment, four stones were placed in pairs

419 on the standing platforms at the top of each tube, and birds could insert them into the functional

420 water tube or non-functional sand-tube.

$421 \quad$ Results: Tequila participated in two trials, inserting 1 stone into the water tube in trial 1 , 422 and 1 stone into first the water tube and then 1 stone in the sand tube in trial 2 . However, he 423 started to refuse to participate in stone dropping all together, therefore I eliminated this 424 experiment and implemented a water tube proficiency assessment to re-motivate him to 425 participate in stone dropping experiments.

427 Water Tube Proficiency Assessment

428 Methods: Upon the implementation of the water tube proficiency assessment for Tequila after 429 the Water vs. Sand experiment, I required this assessment for all of the other birds to ensure a 430 more similar level of water tube experience and to ensure they were able to transfer their stone 431 dropping skills from a platform apparatus to a water tube context. This was likely not necessary

432 for the other grackles though because Tequila transferred his stone dropping skills directly from 433 the platform apparatus to a water tube. Grackles were given a standard tube partially filled with 
434 water with a peanut float and four stones (9-14g, each displaces 5-6mm water), which they could 435 drop into the tube to raise the water level and consequently reach the food. Once a bird 436 accomplished 30 consecutive proficient trials, they moved on to Experiment 3. Proficiency was 437 defined as in the stone dropping training section above.

438 Results: Most grackles immediately applied their stone dropping skills to a water tube 439 context as indicated by their proficiency on their first trial (Cerveza, Margarita, Refresco, and 440 Batido). Horchata was proficient by her second trial. After Tequila's refusal to insert stones into 441 tubes following his Water vs. Sand experiment, he needed 76 trials of water tube proficiency 442 assessment to complete stone insertion proficiency again.

\section{Accidental Object Insertions}

445 Because objects were placed near the top of the tube to allow birds to push objects into the tube, 446 it was also possible to accidentally push or kick an object into the tube. Accidental insertions 447 were noted (see Supplementary Tables S1-S3) and included in analyses because birds could learn 448 about the affordances of the task if an object fell into the water, regardless of whether it was 449 chosen or accidental. Some trials were allowed to consist of only an accidental insertion or 450 insertions because the bird was losing motivation (e.g., refusing to come to the table or interact 451 with the apparatus) and would not have finished the trial otherwise. Counting these as trials errs 452 on the conservative side because throwing the data out and not counting it as a trial removes the 453 ability to account for learning in analyses. 
457 I modified the Aesop's Fable paradigm to test behavioral flexibility by requiring birds to change

458 preferences using four experiments involving two preference changes, similar to reversal

459 learning experiments. In Experiment 3 (Heavy vs. Light), grackles were given heavy and light

460 objects with the former being twice as functional as the latter, therefore grackles should prefer to

461 insert heavy objects if they attend to the functional properties of the task or if they can quickly

462 form an association between the more functional option and success. However, unlike in most

463 previous experiments (e.g., Cheke et al. 2011, Taylor et al. 2011, Jelbert et al. 2014, Logan et al.

464 2014, but see Logan et al. 2016), the light objects sank rather than floated, thus if enough were

465 inserted, the food could be reached. I made this modification so that in Experiment 4 (Heavy vs.

466 Light Magic) when the heavy objects became non-functional by sticking to a magnet placed

467 inside the tube above the water, the light objects would now be the functional option because

468 they could fall past the magnet into the water. Individuals that prefer heavy objects or have no

469 preference in the Heavy vs. Light experiment should change their preference in the Heavy vs.

470 Light Magic experiment to preferring neither object or light objects. This would indicate that

471 their preferences are sensitive to changing contexts.

472 In the Heavy vs. Light experiment, one standard water tube was presented with 4 heavy

473 (steel rod wrapped in fimo clay, weight $=10 \mathrm{~g}$, each displaces $2-3 \mathrm{~mm}$ of water) and 4 light (plastic

474 tube partially filled with fimo clay, weight $=2 \mathrm{~g}$, each displaces $1-1.5 \mathrm{~mm}$ of water) objects placed

475 in pseudorandomized (as explained for the color association test) pairs near the top of the tube

476 (both objects were 21-24mm long and $8 \mathrm{~mm}$ in diameter; Figure 5A). Heavy objects had a larger

477 volume $\left(1,056-1,207 \mathrm{~mm}^{3}\right)$ and displaced $0.5-2 \mathrm{~mm}$ more water than light objects (volume

478 roughly $500 \mathrm{~mm}^{3}$ ), which had a hollow end. Thus the heavy objects were more functional than

479 the light objects, but importantly, both objects were functional. Each bird had three opportunities 
480 to interact with the objects before the experiment began: one heavy and one light object was

481 placed on the table (pseudorandomized for side) with food underneath and on top of each object.

482 The object that was first touched was recorded and a trial continued until the bird interacted with

483 both objects. If one object was preferred (as indicated by approaching it first 2-3 times), then

484 more food was placed on the other object to try to eliminate any object preference before the

485 experiment began. Each grackle needed to choose each object type first at least once during this

486 process, which resulted in Horchata receiving four interactions and Batido five to ensure a lack

487 of preference. After object interaction trials, each bird was given the 20-trial experiment.

488

489

Experiment 3: Results

490 Grackles varied in how efficiently they solved problems. Four grackles (Tequila, Margarita,

491 Batido, and Refresco) were 3.4-5.2 times more likely to choose heavy objects rather than the less

492 functional light objects, while two grackles (Cerveza and Horchata) had no preference (they were

493 0.6-1.4 times more likely to choose heavy objects; see Table 2 for binomial test results and Table

4943 for GLMM results). Cerveza and Horchata's performances improved across trials: they were

495 3.9-4.4 times more likely to choose heavy objects as trial number increased, indicating that they

496 learned through trial and error that the heavy objects were more functional (Table 3). The other

497 grackles' performances did not improve with increasing trial number, indicating that they might

498 have been biased toward heavy objects from the beginning of the experiment or perhaps they

499 used prior knowledge to solve the task (e.g., causal knowledge about functional differences

500 regarding weight or volume; Table 3). Horchata was not motivated to participate in the water

501 tube experiments: she required bait between almost all trials to get her to continue to interact 
502 with the apparatus, which might have influenced her lack of success. All choices in all trials for

503 all birds are presented Supplementary Table S1.

504

505 Experiment 3: Discussion

506 Despite not being a tool-using species, grackles performed well in the tool-using Aesop's Fable

507 paradigm object discrimination tests. Four out of 6 grackles discriminated between object types

508 as indicated by their preference for inserting heavy objects significantly more than light objects.

509 Their object discrimination performance is similar to that in other successful species where

510 individuals preferred to insert heavy objects that sank rather than light objects that floated and

511 thus were not functional at all (Cheke et al. 2011 and 2012, Taylor et al. 2011, Jelbert et al. 2014,

512 Logan et al. 2014). This is in contrast to 4-year-old children who performed poorly by having no

513 object preference (Cheke et al. 2012) and Western scrub-jays who successfully obtained the food

514 but did not discriminate between object types (Logan et al. 2016). Perhaps individuals who

515 discriminated between object types did so because they discriminated between the causal

516 properties of the objects, and thus used causal cognition to solve this task. However, other

517 explanations cannot be ruled out yet: they may have had an initial preference for heavy objects

518 (object bias hypothesis), they might have noticed that inserting a heavy object brings the food

519 closer to the top of the tube than inserting a light object (perceptual-motor feedback hypothesis),

520 or they may have associated retrieving food with the heavy objects (Jelbert et al. 2015).

521 To begin to address the object bias hypothesis, grackles had a modified version of Heavy

522 vs. Light where the light objects, rather than floating and being non-functional, displaced about

523 half the amount of water as the heavy objects (as in Logan et al. 2016). In previous studies

524 testing sinking vs. floating, all participating individuals preferred the sinking objects: $2 / 2$ 
525 Eurasian jays (Cheke et al. 2011), 4/4 New Caledonian crows (Taylor et al. 2011), 6/6 New

526 Caledonian crows (Jelbert et al. 2014), 6/6 New Caledonian crows (Logan et al. 2014), and

527 children age 5 and over (Cheke et al. 2012). Additionally, in a similar Aesop's Fable experiment

528 using objects of the same weight but different volumes (Solid vs. Hollow), all individuals chose

529 the larger volume significantly more: $5 / 5$ New Caledonian crows (Jelbert et al. 2014) and 6/6

530 New Caledonian crows (Logan et al. 2014). This led to the alternative hypothesis that these

531 individuals, rather than attending to function, had a bias toward heavy objects because they were

532 more similar to familiar objects in the wild than the light objects (Logan et al. 2014, Jelbert et al.

533 2015). Making both objects functional, but to different degrees, allowed me to partially test the

534 object bias hypothesis: Rather than making a dichotomous choice where the heavy object was the

535 only functional option, birds could either have an object bias and/or attend more closely to the

536 functional differences in the properties of the objects and choose the heavy object more, or

537 exhibit no object bias by having no object preference and still succeed. Indeed, Western scrub-

538 jays that participated in this modified Heavy vs. Light experiment showed no object preferences,

539 indicating that birds might not have a general bias toward heavy objects (Logan et al. 2016). Two

540 grackles had no object preference and successfully retrieved the reward, which further supports

541 the notion that, at the species level, object biases are not the default. The object bias hypothesis

542 cannot be ruled out for the 4 grackles that preferred to insert heavy objects when both objects

543 were functional. The heavy objects were approximately the same weight as the stones used in

544 stone dropping training, therefore individuals that preferred heavy objects may have relied on an

545 association between weight and function instead of, or in addition to, any similarity the heavy

546 objects might have had to objects in the wild. 
548 the 20 trials in this experiment, indicating that they relied on prior information about the world to 549 solve this task, which suggests that they had an object bias or they may have used causal 550 cognition. Their performance suggests that they did not simply associate the heavy objects with 551 reaching the food because both object types could result in a reward.

552

553 Experiment 4: Heavy vs. Light Magic

554 Experiment 4: Methods

555 The set up was the same as in Experiment 3, except there were magnets (2 super magnets on the 556 outside and 3 on the inside of the tube) attached to the tube above the water level such that the

557 heavy objects would stick to the magnets and not displace water, while the light objects could 558 fall past the magnets into the water, thus being the functional choice (Figure 5B). Birds were 559 given 3 heavy and 3 light objects, placed in pseudorandomized pairs near the top of the tube, and 56020 trials were conducted.

Experiment 4: Results

563 Two grackles exhibited behavioral flexibility by changing their preference from Experiment 3.

564 Tequila and Refresco changed from choosing significantly more heavy objects in Experiment 3

565 to having no object preferences in this experiment (binomial test: $\mathrm{p}=0.60$ and 1.00 , respectively),

566 whereas Batido continued to prefer the non-functional heavy objects (binomial test: $\mathrm{p}=0.02$ ) and

567 Horchata continued to have no object preference (binomial test: $p=1.00$; see Table 2 for binomial

568 test results, Table 3 for GLMM results, and Supplementary Table S2 for all choices made by all

569 birds). Margarita continued to prefer heavy items (binomial test: $p=0.02$ ) and Cerveza went from 
570 having no preference to choosing significantly more non-functional heavy items (binomial test:

$571 \mathrm{p}=0.02$ ) because they exhibited an intense interest in the magnet (Table 2; see a video clip at:

572 https://youtu.be/GhR6fGG1yc4). They repeatedly stuck heavy objects to the magnet and

573 attempted to pull them off, requiring almost no rewards between trials for participating, which

574 indicated a high degree of motivation (motivation that rapidly decreases if they fail experiments).

575 The experiment did not have the intended effect on their behavior. Tequila gave up after 17

576 trials, refusing to drop either type of object into the tube, indicating he may have inhibited his

577 heavy preference while at the same time not persisting with the light objects. Tequila and

578 Refresco's performance improved with trial number, indicating that they learned through trial

579 and error about which object was functional (Table 3). The other grackle's performances did not

580 change or they decreased with increasing trial number, indicating that they did not learn about

581 which object was functional (Table 3). Even though Tequila and Refresco did not learn to prefer

582 light objects in the amount of trials given, they did exhibit flexibility in that they changed their

583 preferences from heavy in the previous experiment to having no preference in this experiment.

584

585 Experiment 4: Discussion

586 Behavioral flexibility was exhibited by grackles because they changed their preferences when the

587 task changed. When the heavy objects in the Heavy vs. Light Magic experiment were no longer

588 functional because they stuck to a magnet, 2 grackles changed from having preferred heavy

589 objects when they were functional in Heavy vs. Light to having no object preference in the

590 Magic experiment. This demonstrates either an attention to the functional properties of objects or

591 that some grackles who previously might have been biased toward heavy objects were able to

592 counteract this bias in light of new associative information (i.e., associating light objects with the 
593 previously rewarded movement of an object falling into the water). Either way, their behavior

594 changed when circumstances changed.

595 No grackle completely switched their preference to the light objects, which may have

596 been due to the difficult design of the apparatus, both theoretically and physically. Theoretically,

597 this experiment is similar to the U-tube Aesop's Fable experiment where birds that rely on causal

598 cues to solve these kinds of tasks should fail because no causal information is available about

599 how the apparatus works (Cheke et al. 2011, Jelbert et al. 2014, Logan et al. 2014). Instead, birds

600 must rely solely on associative cues to solve the task (e.g., dropping stones into the blue tube

601 results in a reward in its adjacent tube). If birds generally solve these kinds of problems

602 associatively, then they should learn this association at a similar rate to other Aesop's Fable

603 experiments. However, if birds rely to some degree on causal cues to solve these problems, then

604 their learning speed should be impeded. The grackle's lack of learning to associate light objects

605 with a food reward may have been partially due to an attendance to causal cues when solving

606 these tasks. The apparatus was difficult physically as well: if one heavy item was inserted into

607 the tube, it stuck to the magnet and blocked access to the food regardless of how many light

608 objects were inserted. Thus, grackles had to inhibit inserting any heavy objects to solve this

609 problem, which made the task difficult. Tequila and Refresco's performance is consistent with

610 previous interpretations of Eurasian jay behavior on the U-tube apparatus: they were slow to

611 learn from associative cues when only associative information was available, therefore they

612 likely rely to a degree on causal cues when solving these tasks (Cheke et al. 2011). However, in

613 the case of the grackles, I cannot rule out that the physical difficulty of the apparatus was the

614 cause of their slow learning, which, if addressed, might have resulted in their quickly learning

615 this task using associative cues. 


\section{Experiment 5: Narrow vs. Wide Equal Water Levels}

618 Experiment 5: Methods

619 Experiments 5 and 6 followed the same methods used for New Caledonian crows (Logan et al. 620 2014). To solve Experiment 5, objects must be inserted into a narrow (functional) rather than a 621 wide (non-functional) tube when water levels are equal in both tubes. In Experiment 6 , the 622 narrow tube becomes non-functional because the water level is too low, therefore birds must 623 change their preference to inserting objects into the functional wide tube or to having no 624 preference (as long as they successfully reach the food in most trials) to demonstrate behavioral 625 flexibility.

626 To determine whether birds attend to volume differences in Experiment 5, a wide tube 627 and a narrow tube with equal water levels were presented with four objects made out of fimo 628 clay $(30 \times 10 \times 5 \mathrm{~mm}, 3-4 \mathrm{~g}$, each object displaced $1-2 \mathrm{~mm}$ in the wide tube and $5-6 \mathrm{~mm}$ in the narrow 629 tube; Logan et al. 2014; Figure 6). Two objects were placed on the platform near the narrow tube 630 opening and two objects on the platform near the wide tube opening. The objects were functional 631 only if dropped into the narrow tube because the water levels were set such that dropping all of 632 the objects into the wide tube would not bring the floating food within reach. However, dropping 633 1-2 objects into the narrow tube would raise the water level enough to reach the food. Both tubes

634 were $170 \mathrm{~mm}$ tall with $3 \mathrm{~mm}$ thick lids that constricted the opening to $25 \mathrm{~mm}$ in diameter to 635 equalize the bird's access to the inside of each tube, and super glued to a clear acrylic base $636(300 \times 300 \times 3 \mathrm{~mm})$. The wide tube (outer diameter $=57 \mathrm{~mm}$, inner diameter $=48 \mathrm{~mm}$, 637 volume $=307,625 \mathrm{~mm}^{3}$ ) was roughly equally larger than the standard water tube (dimensions 638 above, volume $=192,800 \mathrm{~mm}^{3}$ ) as the narrow tube was smaller (outer diameter $=38 \mathrm{~mm}$, inner 
639 diameter $=25 \mathrm{~mm}$, volume $=83,449 \mathrm{~mm}^{3}$ ). The position of the tubes was pseudorandomized for side

640 to ensure that tube choices were not based on a side bias, and 20 trials were conducted. Before

641 the experiment began, each bird had three opportunities to interact with the object, as in

642 Experiment 3, only here it was simply to habituate them to the clay object (one object type) and 643 not to train the birds not to prefer one object type over another.

\section{Experiment 5: Results}

646 Grackles did not discriminate between water volumes, indicating they were not efficient problem 647 solvers in this context. All three grackles that participated in this experiment displayed no 648 preference for dropping objects into the functional narrow tube or the non-functional wide tube 649 (binomial test: $\mathrm{p}=1.00$ for every bird, Table 2; see Table 3 for GLMM results, and 650 Supplementary Table S3 for all choices by all birds). None of the grackles' performances 651 improved with trial number, indicating that they did not learn to distinguish which tube was 652 functional (Table 3). Batido appeared to rely on the strategy of dropping all objects into both 653 tubes regardless of which tube he received a reward from, although in trial 12 , he picked up the 654 objects from the wide tube area and dropped them into the narrow tube even though he was 655 trained to only push stones, not drop them (Supplementary Table S3).

656 Some grackles did not initially transfer from dropping previous object types to dropping 657 the clay objects used in this experiment. It appeared as though they were trying to solve the 658 problem, but did not perceive the clay objects as being the kind of object one would drop into a 659 water tube. In these cases, additional training was implemented using a single standard water 660 tube and a mixture of clay objects and stones until the bird was willing to drop objects into the 661 tube even if they consisted only of clay objects. Cerveza transferred to dropping clay objects 
662 after 4 training trials, but Tequila and Margarita were excluded from this experiment because

663 they did not transfer to dropping clay objects into tubes. After 14 training trials on a regular

664 water tube with stones and clay objects available to Tequila, it was clear that it would take many 665 more training trials than there was time for because his motivation was greatly diminished. 666 Margarita refused to participate in the training trials. Horchata was also excluded from this 667 experiment because she refused to interact with the objects.

668

669 Experiment 5: Discussion

670 Grackles did not discriminate between water volumes in the Narrow vs. Wide equal water level 671 experiment. Perhaps their skill in water displacement experiments is limited to objects, however 672 more experiments involving object and tube properties would need to be conducted to confirm 673 this.

674

675 Experiment 6: Narrow vs. Wide Unequal Water Levels

676 Experiment 6: Methods

677 Those grackles that passed Experiment 5 continued to this experiment to determine whether their 678 tube choices adjusted to changing circumstances. This experiment was the same as Experiment 6795 , except the water level in the narrow tube was lowered to $5 \mathrm{~cm}$ from the table, thus making the 680 food unreachable even if all objects were dropped into this tube (as in Logan et al. 2014). The 681 water level in the wide tube was raised such that the bird could reach the food in $1-4$ object 682 drops, and 20 trials were conducted.

683

684 Experiment 6: Results 
685 No grackle passed Experiment 5, indicating they were not sensitive to the differences in water 686 volumes; therefore they were not given Experiment 6, which would have investigated their 687 behavioral flexibility in this context.

688

689

Experiment 6: Discussion

690 While grackles were not given experiment 6, it is interesting to compare their behavioral 691 flexibility in the Heavy vs. Light experiments with New Caledonian crow performances in the 692 Narrow vs. Wide experiments because crows previously showed behavioral flexibility in this 693 context (New Caledonian crows were not given the Heavy vs. Light Magic experiment because it 694 was not invented yet, which is why I cannot directly compare their behavioral flexibility 695 performances). Four out of $6 \mathrm{New}$ Caledonian crows preferred to drop objects into the functional 696 narrow tube rather than the non-functional wide tube. When the wide tube became the functional 697 option, 3 New Caledonian crows changed their preference to the wide tube and 1 changed to no 698 preference (Logan et al. 2014). Grackle performances in the Heavy vs. Light experiments were 699 similar to the New Caledonian crow that changed from narrow to no preference in the Narrow 700 vs. Wide experiments.

701

702 Context 2: First Choices on First Trials

703 First trial performance on tasks that can involve more than trial and error learning is considered

704 an important feature when evaluating cognitive performance because it gives an indication of 705 what the individuals might infer about the task. All six grackles chose the more functional heavy 706 objects as their first choice in their first trial in Heavy vs. Light, which indicates that they 707 preferred the heavy objects from the very beginning of the experiment (Supplementary Table 
708 S1). Five out of six grackles chose the non-functional heavy objects in Heavy vs. Light Magic

709 (Supplementary Table S2), which is not surprising given that they had learned to prefer heavy

710 objects in the previous experiment and had likely never interacted with a magnet before,

711 therefore they should have had no reason to have a prior understanding of how the Magic

712 experiment worked. Two out of three grackles chose the functional narrow tube in Narrow vs.

713 Wide with equal water levels, indicating no group-level initial preference for a particular tube

714 (Supplementary Table S3).

715

716 Context 2: Did choice number influence the results?

717 Individuals could learn how the water tube tasks worked with each choice they made, potentially

718 making each choice dependent on previous choices. Multiple choices could be made per trial;

719 therefore I analyzed how independent choice number was. Choice number was modeled as a

720 random factor in the GLMM and did not influence the results, indicating that choices appear

721 independent of each other (Table 3). This result combined with the result that some individuals

722 increased their success across the 20-trials, indicates that learning occurred at the trial level, not

723 at the level of individual choices. Perhaps learning was linked to the receipt of a food reward,

724 which was obtained near the end of a trial, rather than the movement of the food in the tube,

725 which could occur with each choice.

726

727 Did behavioral flexibility correlate across contexts?

728 Those grackles that were more behaviorally flexible in the Aesop's Fable context (i.e., changed

729 preferences) were not more behaviorally flexible in the color association context (i.e., faster to 
730 reverse a previously learned preference; Spearman's rank correlation test: $S=28.89, p=0.45$,

731 rho=-0.44, $\mathrm{n}=5$; Table 4).

732

733 GENERAL DISCUSSION

734 Grackles demonstrated behavioral flexibility in two contexts, the Aesop's Fable paradigm and a

735 color association test. Contrary to predictions, behavioral flexibility did not correlate across

736 contexts: Those grackles that exhibited flexibility in the Aesop's Fable paradigm were not the

737 fastest to reverse a previously learned color preference in the color association test. Four out of 6

738 grackles exhibited efficient problem solving abilities, similar to other successful species, by

739 choosing heavy objects significantly more in the Heavy vs. Light experiment. Problem solving

740 efficiency did not appear to be directly linked with behavioral flexibility because not all grackles

741 (2/4) that were efficient problem solvers changed their preference in the Aesop's Fable

742 paradigm. Problem solving speed (Experiment 1) also did not significantly correlate with

743 reversal learning scores (Experiment 2), indicating that faster learners were not the most flexible.

744 The lack of correlations within and across contexts for behavioral flexibility and for

745 behavioral flexibility and problem solving supports the hypothesis that behavioral flexibility is

746 not only an independent source of variation distinct from problem solving ability and speed

747 (Cole et al. 2011), but also independent across contexts (Griffin \& Guez 2014). This finding

748 suggests that investigations of behavioral flexibility should conduct multiple tests of behavioral

749 flexibility in different contexts to more fully understand how it relates to itself, cognition, and

750 other variables of interest (Griffin and Guez 2014). Maintaining many independent sources of

751 variation in a population could be useful for successfully adapting to new environments. Western

752 bluebirds were found to rely on a range of dispersal strategies that already existed in their 
753 population when colonizing a new habitat (Duckworth 2008). Thus, the more sources of

754 variation a population can access, the more likely it is that at least some of this variation will suit

755 the new situation and allow the species to adapt.

756 One potential explanation for why individuals varied in behavioral flexibility across

757 contexts regards the type of cognition used in each context. Causal cognition and/or trial and

758 error learning based on multiple cues (e.g., object type, movement of the food with each object

759 drop) could be used to solve the Aesop's Fable tasks (Experiments 3-6), whereas only trial and

760 error learning based on one cue (i.e., color) could be used to solve the color association tasks

761 (Experiments 1-2). If individuals varied in the kinds of cues they attended to this might have

762 caused the differences in performance across contexts. Such individual variation in attention to

763 particular cues was found in Eurasian jays (Cheke et al. 2011). Behavioral flexibility will need to

764 be tested in more contexts to determine whether individual differences are due to differential cue

765 use or different contexts.

766 A higher number of learning strategies in the color association tests did not necessarily

767 indicate flexibility in the color association context or the Aesop's Fable context. Refresco was

768 one of the two behaviorally flexible individuals in the water tube experiments (3-4), and about

769 average in reversing a color preference (Experiment 2; Table 4). He was also the only grackle to

770 use more than one learning strategy in the color association experiments: he used the epsilon-first

771 strategy to sample the environment once before arriving at the correct solution and then he

772 stayed with the correct choice for the rest of Experiment 1. He then switched his learning

773 strategy to epsilon-decreasing for his color association refresher and for reversal learning

774 (Experiment 2), which is the same strategy the rest of the birds used in Experiments 1 and 2.

775 Individuals using the epsilon-decreasing strategy sample the environment extensively before 
776 consistently making the correct choice. Because there was almost no individual variation in

777 learning strategies it is difficult to understand how this trait covaries with behavioral flexibility.

778 However, it suggests that a variety of learning strategies is not required for a large amount of

779 variation in behavioral flexibility, problem solving ability, and problem solving speed to exist in 780 a population.

781 That behavioral flexibility did not correlate across contexts or with problem solving 782 ability (Experiment 3 ) or speed (Experiment 1) reveals how little we know about behavioral 783 flexibility, and provides an immense opportunity for future research to explore how individuals 784 and species can use behavior to react to changing environments.

785

786 ACKNOWLEDGEMENTS

787 I am grateful to Luisa Bergeron, Christin Palmstrom, Linnea Palmstrom, and Michelle Gertsvolf

788 for trapping and aviary assistance; Alexis Breen for helping to train Jugo; Brigit Harvey for stone 789 dropping training consultations; Steve Rothstein for scouting grackles and for use of the aviaries;

790 Joe Jablonski and David Bothman for making the apparatuses; Jill Zachary and Kathy Frye at

791 Santa Barbara City Parks and Recreation for use of the Andree Clark Bird Refuge and East

792 Beach Park; Estelle Sandhaus and Chris Briggs at the Santa Barbara Zoo for access to wild 793 grackles; Karrie Black for managing purchasing and grants; Alex Thornton for logistical advice;

794 Dieter Lukas for conceptual input and analysis feedback, Alecia Carter for manuscript 795 restructuring advice, and the rest of LARG for feedback; Krista Fahy at the Santa Barbara 796 Museum of Natural History for helping with permit applications; Kristine Johnson, Sarah 797 Overington, Julie Morand-Ferron, and Neeltje Boogert for grackle advice and trap plans and 798 manuscript feedback; Manny Garcia for veterinary and permit support; Mary Hunsicker and 
799 Bertrand Lemasson for assistance with making the trap; Margaret Tarampi, Eric Egenolf,

800 Rebecca Schaefer, and Sam Franklin for brainstorming object designs; Will Hoppitt for GLMM

801 effect size interpretation assistance; and Irina Mikhalevich, Ljerka Ostojić, Jennifer Vonk, Zoe

802 Johnson-Ulrich, and an anonymous reviewer for manuscript feedback.

803

804 REFERENCES

805 Akaike H. 1981. Likelihood of a model and information criteria. Journal of

806 Econometrics 16:3-14 doi:10.1016/0304-4076(81)90071-3

807

808

809

810

811

812

813

814

815

816

817

818

819

820

821

Auersperg, AMI, von Bayern AMP, Gajdon GK, Huber L, Kacelnik, A. 2011.

Flexibility in problem solving and tool use of kea and New Caledonian crows in a multi access box paradigm. PloS One 6:e20231. doi:10.1371/journal.pone.0020231

Bates D, Maechler M, Bolker B. 2011. lme4: Linear mixed-effects models using S4 classes. R package version 0.999375-42. http://CRAN.R-project.org/package=lme4. Accessed 12 January 2016

Bebus, SE, Small TW, Jones, BC, Elderbrock EK, Schoech SJ. 2016. Associative learning is inversely related to reversal learning and varies with nestling corticosterone exposure. Animal Behaviour 111:251-260 doi: 10.1016/j.anbehav.2015.10.027

Bird CD, Emery NJ. 2009. Rooks use stones to raise the water level to reach a floating worm. Current Biology 19:1410-1414 doi:10.1016/j.cub.2009.07.033

Bond AB, Kamil AC, Balda RP. 2007. Serial reversal learning and the evolution of behavioural flexibility in three species of North American corvids (Gymnorhinus cyanocephalus, Nucifraga columbiana, Aphelocoma californica). Journal of Comparative Psychology 121:372 doi:10.1037/0735-7036.121.4.372 
822 Buckner C. 2013. A property cluster theory of cognition. Philosophical Psychology 28:307-336

823 doi: $10.1080 / 09515089.2013 .843274$

824 Burnham KP, Anderson DR. 2002. Model selection and multimodel inference: a practical 825 information- theoretic approach, 2nd edn. New York, NY: Springer.

826 Cheke LG, Bird CD, Clayton NS. 2011. Tool-use and instrumental learning in the Eurasian jay 827 (Garrulus glandarius). Animal Cognition 14:441-455 doi:10.1007/s10071-011-0379-4

828 Cheke LG, Loissel E, Clayton NS. 2012. How do children solve Aesop's Fable? PLoS ONE 829 7:e40574 doi:10.1371/journal.pone.0040574

830 Chow PKY, Lea SE, Leaver LA. 2016. How practice makes perfect: the role of persistence, flexibility and learning in problem-solving efficiency. Animal Behaviour 112:273-283 doi: 10.1016/j.anbehav.2015.11.014

833 Clayton NS, Dickinson A. 1998. Episodic-like memory during cache recovery by scrub jays. Nature 395:272-274 doi:10.1038/26216

Dally JM, Emery NJ, Clayton NS. 2006. Food-caching western scrub-jays keep track of who was watching when. Science 312:1662-1665 doi:10.1126/science.1126539

Duckworth RA. 2008. Adaptive dispersal strategies and the dynamics of a range expansion. The American Naturalist 172:S4-S17 doi:10.1086/588289

Ghahremani DG, Monterosso J, Jentsch JD, Bilder RM, Poldrack RA. 2010. Neural components underlying behavioural flexibility in human reversal learning. Cerebral Cortex 20:1843-1852 doi:10.1093/cercor/bhp247

842 Griffin AS, Guez D. 2014. Innovation and problem solving: a review of common mechanisms. 843 Behavioural Processes 109:121-134 doi:10.1016/j.beproc.2014.08.027 
844 Griffin AS, Guez D, Lermite F, Patience M. 2013. Tracking changing environments:

$845 \quad$ Innovators are fast, but not flexible learners. PLoS ONE 8:e84907

846 doi:10.1371/journal.pone.0084907

847 Hadfield J. 2010. MCMCglmm: Markov chain Monte Carlo methods for generalised linear $848 \quad$ mixed models.

849 http://citeseerx.ist.psu.edu/viewdoc/download;jsessionid=E395FF7367BF580D916E465F

$850 \quad 55302 \mathrm{C} 60 ? \mathrm{doi}=10.1 .1 .160 .5098 \& \mathrm{rep}=\mathrm{rep} 1 \&$ type=pdf Accessed 7 May 2015

851 Hadfield J. 2014a. MCMCglmm: MCMC generalised linear mixed models. R package.

852 https://cran.r-project.org/web/packages/MCMCglmm/index.html Accessed 30 July 2015

853 Hadfield J. 2014b. MCMCglmm course notes. http://cran.r-

854 project.org/web/packages/MCMCglmm/vignettes/CourseNotes.pdf. Accessed 7 May

$855 \quad 2015$

856 Isden J, Panayi C, Dingle C, Madden J. 2013. Performance in cognitive and problem-solving

857 tasks in male spotted bowerbirds does not correlate with mating success. Animal

$858 \quad$ Behaviour 86:829-838. doi:10.1016/j.anbehav.2013.07.024

859 Jelbert SA, Taylor AH, Cheke LG, Clayton NS, Gray, RD. 2014. Using the Aesop's fable

860 paradigm to investigate causal understanding of water displacement by New Caledonian

$861 \quad$ crows. PLoS ONE 9:e92895 doi:10.1371/journal.pone.0092895

862 Jelbert SA, Taylor AH, Gray RD. 2015. Investigating animal cognition with the Aesop's Fable

863 paradigm: Current understanding and future directions. Communicative \& Integrative

$864 \quad$ Biology 8:e1035846 doi:10.1080/19420889.2015.1035846

865 Lefebvre L, Whittle P, Lascaris E, Finkelstein A. 1997. Feeding innovations and forebrain

866 size in birds. Animal Behaviour 53:549-560 doi:10.1006/anbe.1996.0330 
867 Lefebvre L, Nicolakakis N, Boire D. 2002. Tools and brains in birds. Behaviour 139:939-973

$868 \quad$ doi:10.1163/156853902320387918

869 Lissek S, Diekamp B, Güntürkün O. 2002. Impaired learning of a colour reversal task after

870 NMDA receptor blockade in the pigeon (Columba livia) associative fore-brain

871 (Neostriatum Caudolaterale). Behavioral Neurosciences 116:523-529 doi:10.1037//0735-

$872 \quad 7044.116 .4 .523$

873 Liu Y, Day LB, Summers K, Burmeister SS. 2016. Learning to learn: advanced behavioural flexibility in a poison frog. Animal Behaviour 111:167-172.

875 doi:10.1016/j.anbehav.2015.10.018

Logan C. 2015. Great-tailed grackle behavioral flexibility and problem solving experiments, Santa Barbara, CA USA 2014-2015. KNB Data Repository. https://knb.ecoinformatics.org/\#view/corina_logan.15.6

Logan CJ, Harvey B, Schlinger BA, Rensel M. 2016. Western scrub-jays do not appear to 880 attend to functionality in Aesop's Fable experiments. PeerJ 4:e1707 doi:

881 10.7717/peerj.1707

882

Logan CJ, Jelbert SA, Breen AJ, Gray RD, Taylor AH. 2014. Modifications to the Aesop's 883 Fable paradigm change performances in New Caledonian crows. PLoS ONE 9:e103049 doi:10.1371/journal.pone.0103049

Manrique HM, Völter CJ, Call J. 2013. Repeated innovation in great apes. Animal Behaviour 85:195-202 doi:10.1016/j.anbehav.2012.10.026

McInerney RE. 2010. Multi-Armed Bandit Bayesian Decision Making. University of Oxford, 888 Oxford: Technical Report. 
889 Overington SE, Cauchard L, Cote KA, Lefebvre L. 2011. Innovative foraging behaviour in 890 birds: What characterizes an innovator? Behavioural Processes 87:274-285

$891 \quad$ doi:10.1016/j.beproc.2011.06.002

892 Peer BD. 2011. Invasion of the emperor's grackle. Ardeola 58:405-409

893 doi:10.13157/arla.58.2.2011.405

894 Pyle P. 2001. Identification Guide to North American Birds Part 1. Ann Arbor, MI: Sheridan 895 Books, Inc.

R Core Team. 2016. $R$ : A language and environment for statistical computing. R Foundation for Statistical Computing, Vienna, Austria. https://www.R-project.org.

Raby CR, Alexis DM, Dickinson A, Clayton NS. 2007. Planning for the future by western scrub-jays. Nature 445:919-921 doi:10.1038/nature05575

Seed AM, Tebbich S, Emery NJ, Clayton NS. 2006. Investigating physical cognition in rooks, Corvus frugilegus. Current Biology 16:697-701 doi:10.1016/j.cub.2006.02.066

Sol D, Duncan RP, Blackburn TM, Cassey P, Lefebvre L. 2005. Big brains, enhanced 903 cognition, and response of birds to novel environments. Proceedings of the National Academy of Sciences 102:5460-5465 doi:10.1073 $\square$ pnas.0408145102

Sol D, Lefebvre L. 2000. Behavioural flexibility predicts invasion success in birds introduced to 906 New Zealand. Oikos 90:599-605 doi:10.1034/j.1600-0706.2000.900317.x

907 Sol D, Székely T, Liker A, Lefebvre L. 2007. Big-brained birds survive better in nature. Proceedings of the Royal Society of London B 274:763-769 doi:10.1098/rspb.2006.3765

Sol D, Timmermans S, Lefebvre L. 2002. Behavioural flexibility and invasion success in birds. Animal Behaviour 63:495-502 doi:10.1006/anbe.2001.1953 
911 Taylor AH, Elliffe DM, Hunt GR, Emery NJ, Clayton NS, Gray RD. 2011. New Caledonian

912 crows learn the functional properties of novel tool types. PLoS ONE 6:e26887

913 doi:10.1371/journal.pone.0026887

914 Tebbich S, Seed AM, Emery NJ, Clayton NS. 2007. Non-tool-using rooks, Corvus frugilegus, 915 solve the trap-tube problem. Animal Cognition 10:225-231 doi: 10.1007/s10071-006-

$916 \quad 0061-4$

917 Tebbich S, Sterelny K, Teschke I. 2010. The tale of the finch: Adaptive radiation and

918 behavioural flexibility. Philosophical Transactions of the Royal Society B 365:1099-1109

919 doi:10.1098/rstb.2009.0291 


\section{Figure 1 (on next page)}

Learning strategies used during Experiment 1

Learning strategies employed by grackles when learning to associate the gold tube with food in Experiment 1 as shown by the proportion of correct choices (non-overlapping sliding window of 4-trial bins) across the number of trials required to reach the criterion of $17 / 20$ correct choices. 
Tequila Michelada Margarita

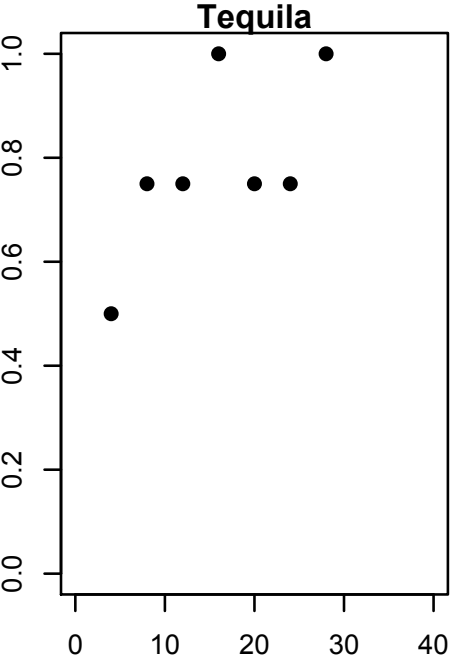

Horchata

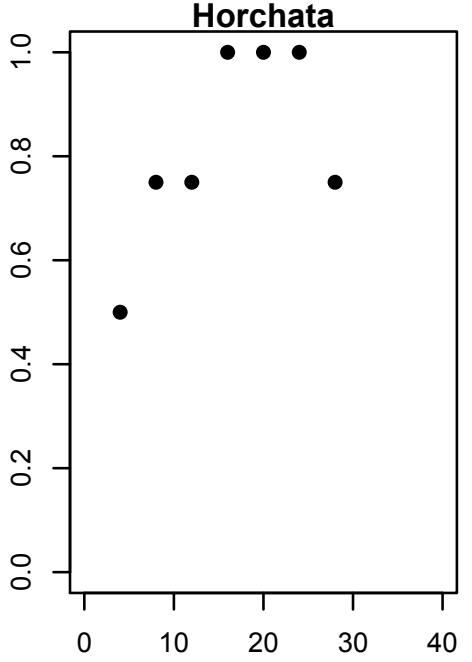

Trial

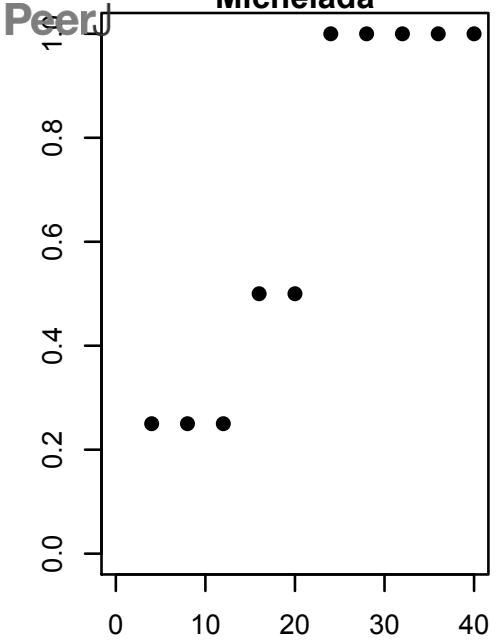

Refresco

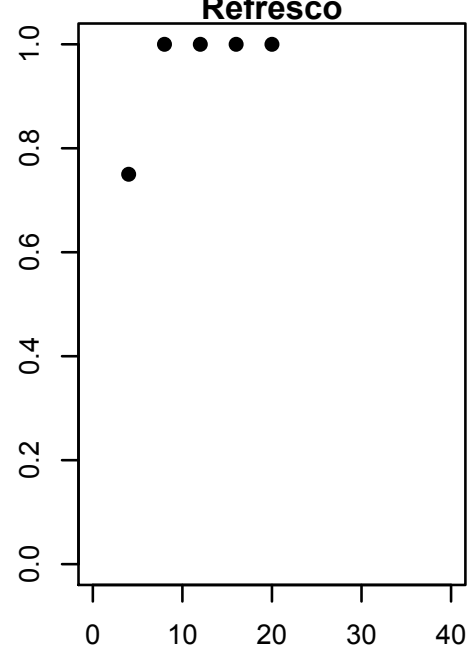

Peerf reviewing PDF | (2016:03:9426:2:0:NEW 4 Apr 2016) Trial
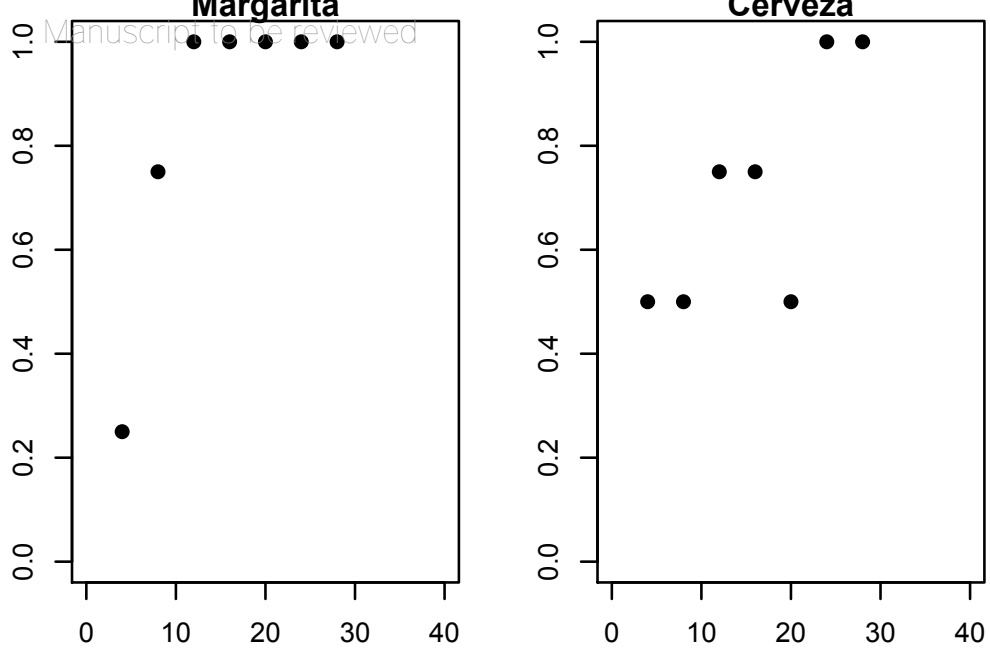

Batido

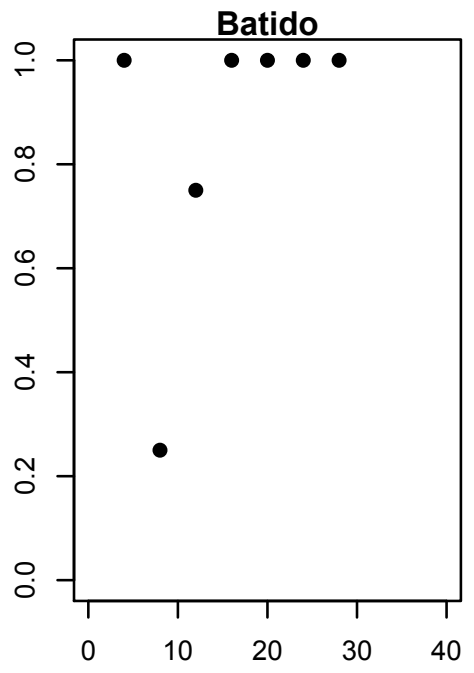

Trial

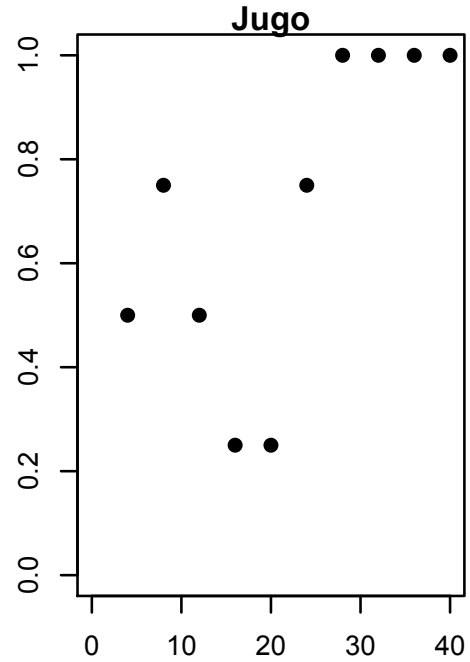

Trial 


\section{Figure 2 (on next page)}

Learning strategies used during the Experiment 1 refresher

Learning strategies employed by grackles when checking whether they remember that the gold tube contained the food as shown by the proportion of correct choices (non-overlapping sliding window of 4-trial bins) across the number of trials required to reach the criterion of $17 / 20$ correct choices. 

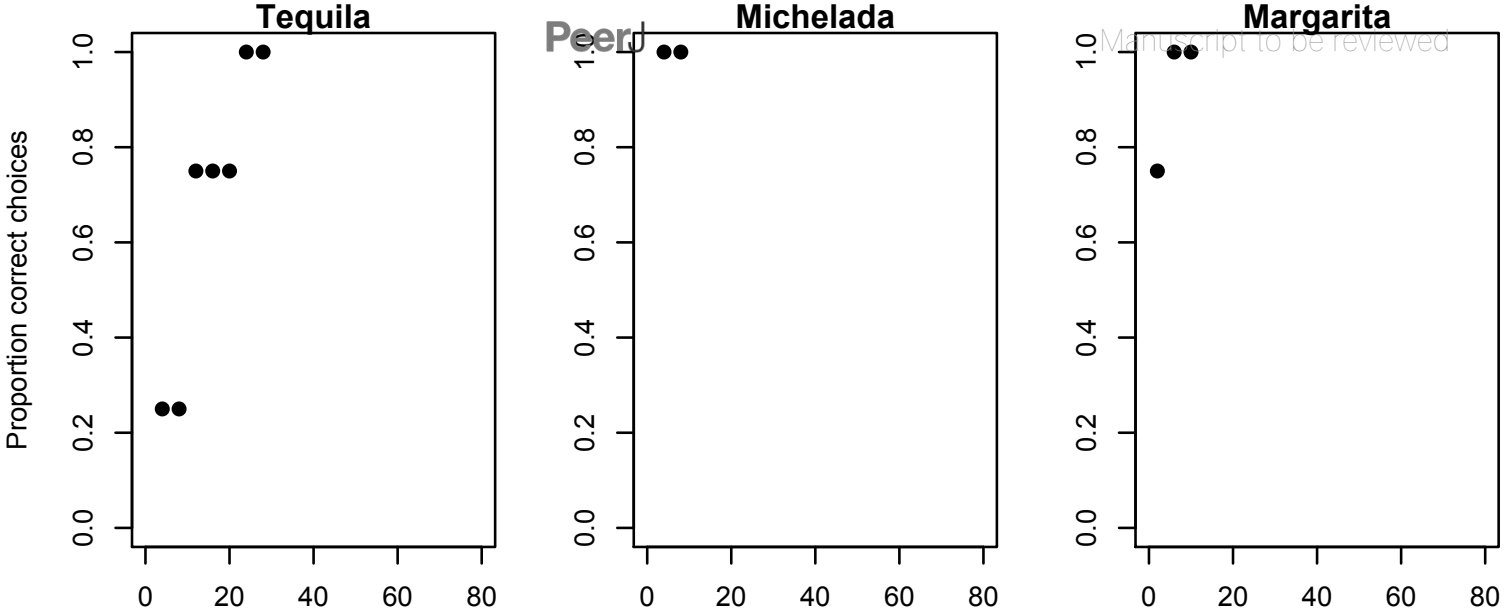

○. Cerveza
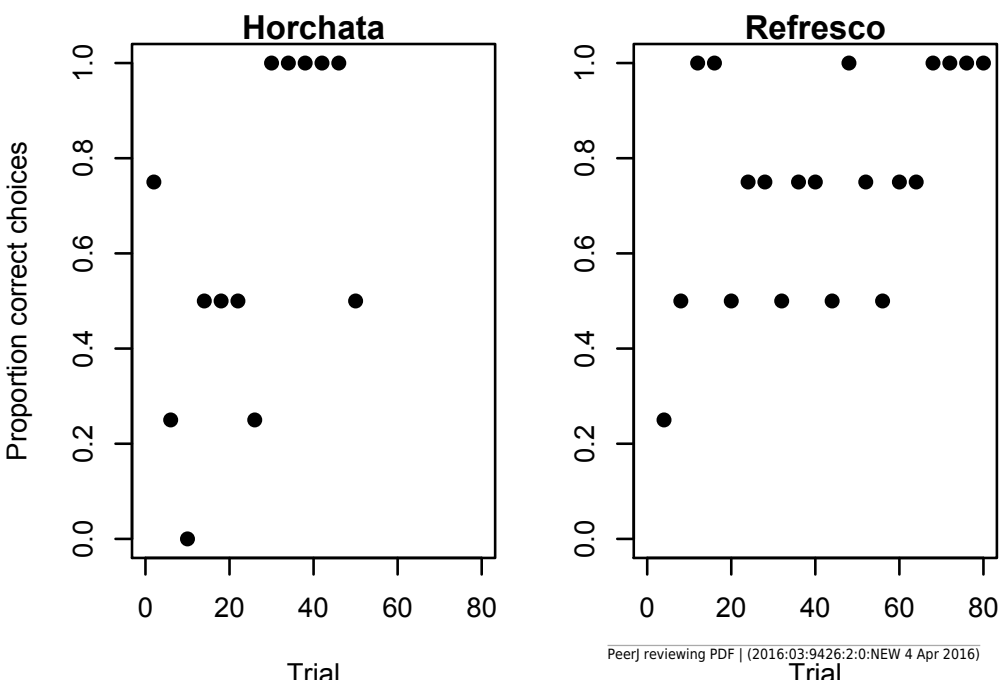

Batido

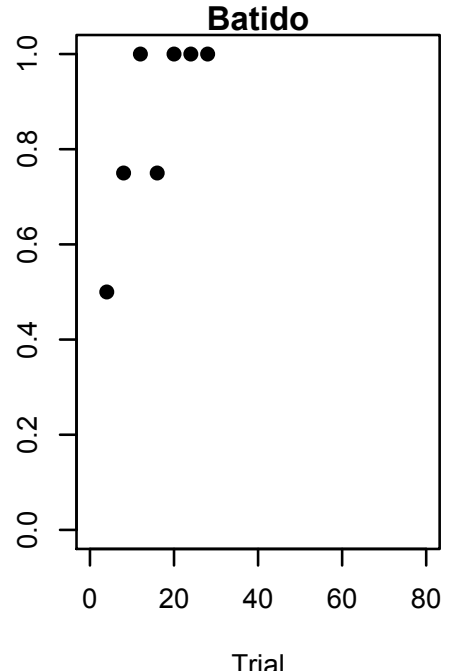

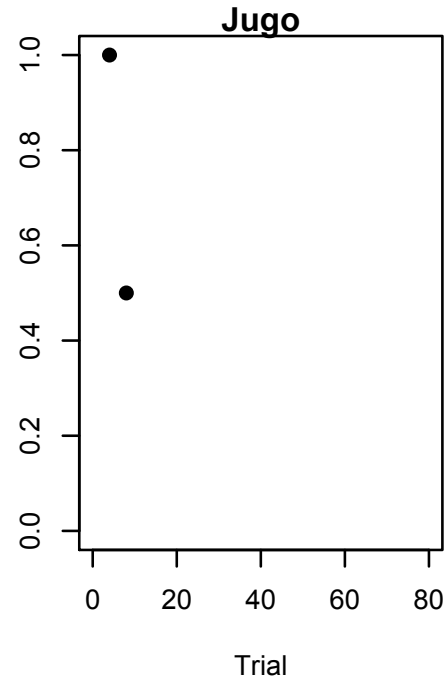




\section{Figure 3 (on next page)}

Learning strategies used during reversal learning in Experiment 2

Learning strategies employed by grackles when learning to associate the silver tube with food, rather than their previously learned association between the gold tube and food, as shown by the proportion of correct choices (non-overlapping sliding window of 4-trial bins) across the number of trials required to reach the criterion of 17/20 correct choices. 
4

Stone dropping training using a platform apparatus

Batido inserted a stone into the stone dropping training apparatus, which collapsed the platform and the peanut float fell out onto the table.

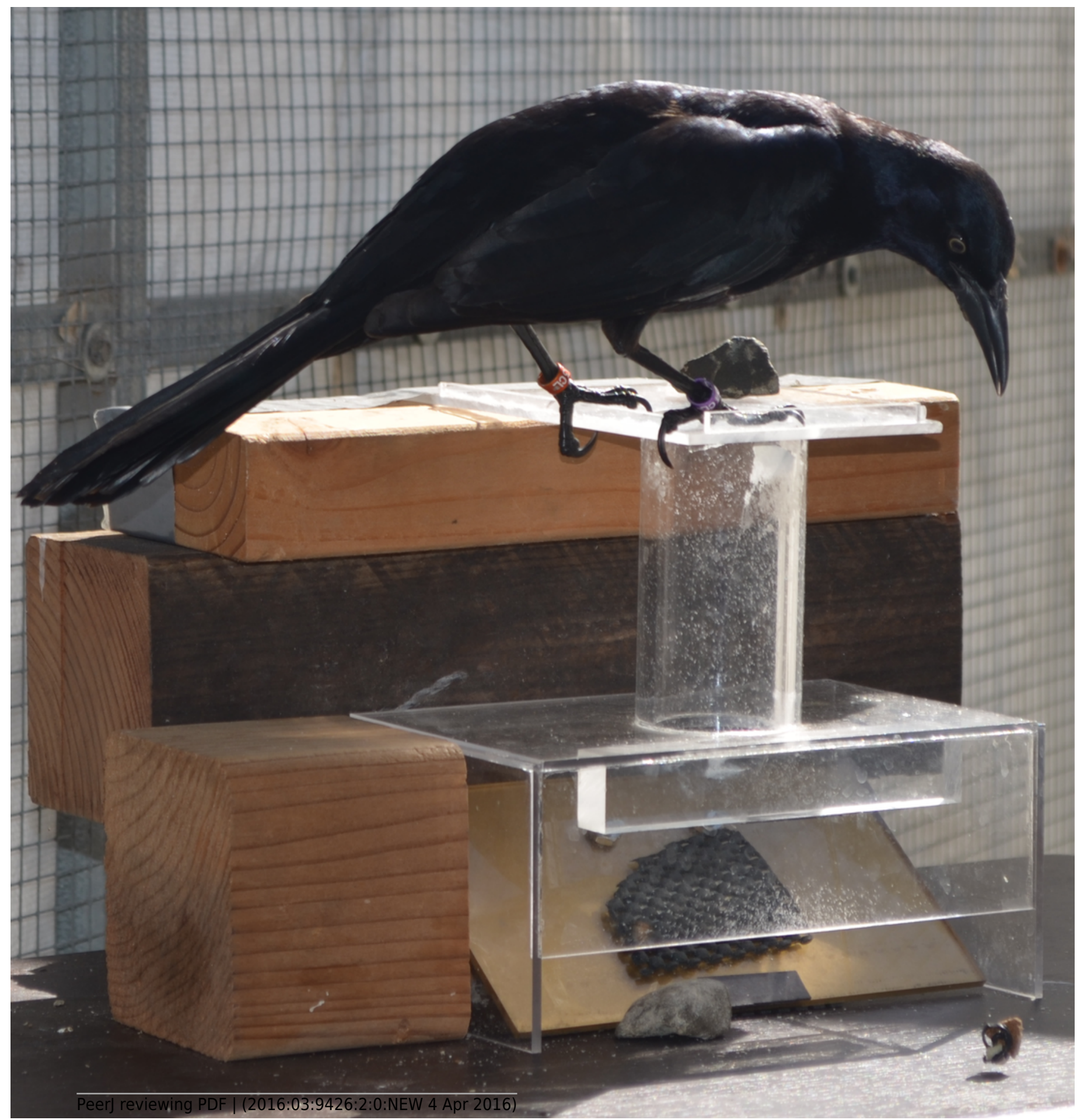


5

Heavy vs. Light (A) and Heavy vs. Light Magic (B)

Heavy objects are more functional than light objects in the Heavy vs. Light experiment (A), while the light objects are the only functional objects in the Heavy vs. Light Magic experiment (B).

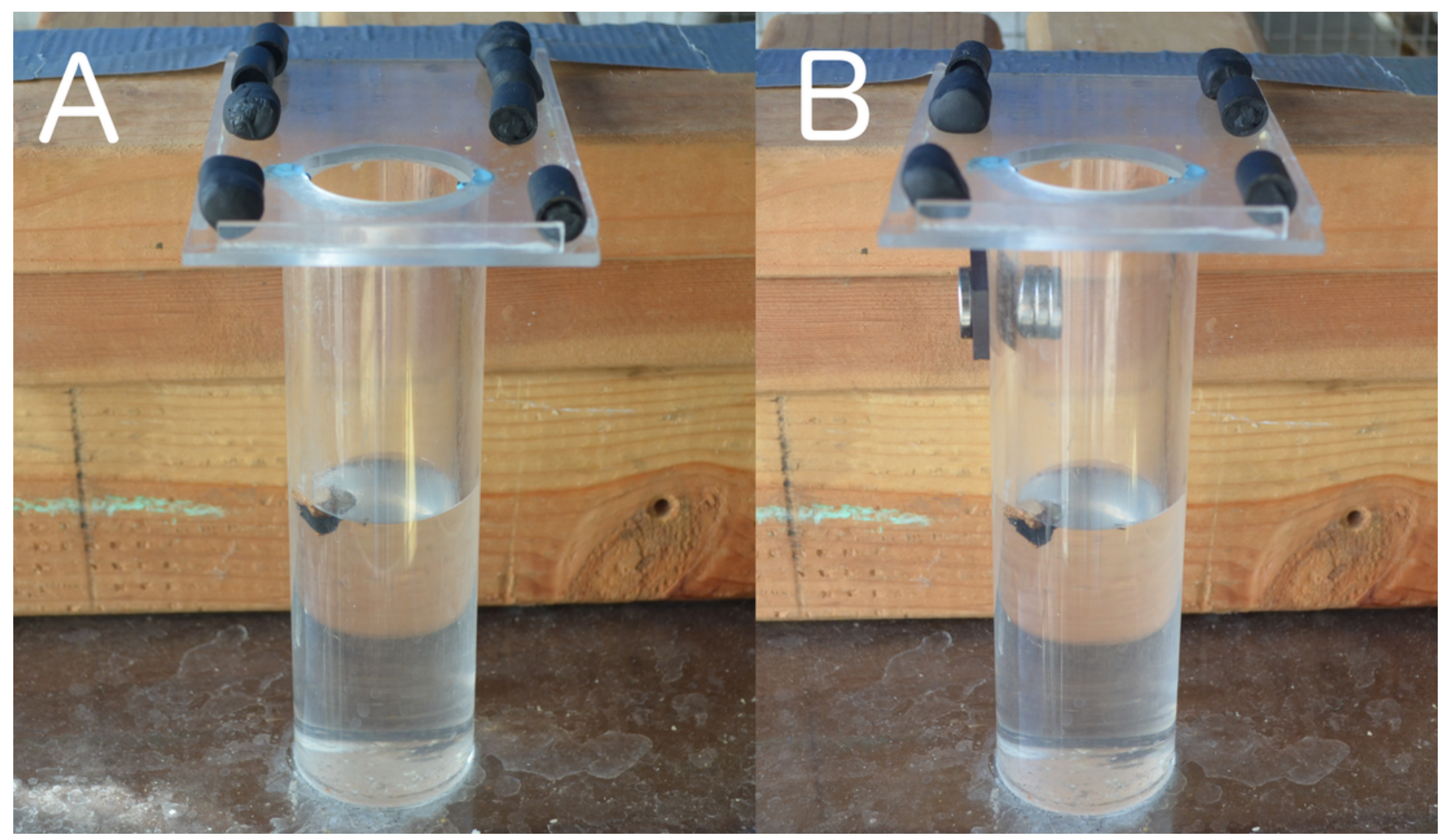


6

Narrow vs. Wide

Dropping clay objects into the narrow tube in the Narrow vs. Wide equal water level experiment is the only way to reach the floating food.

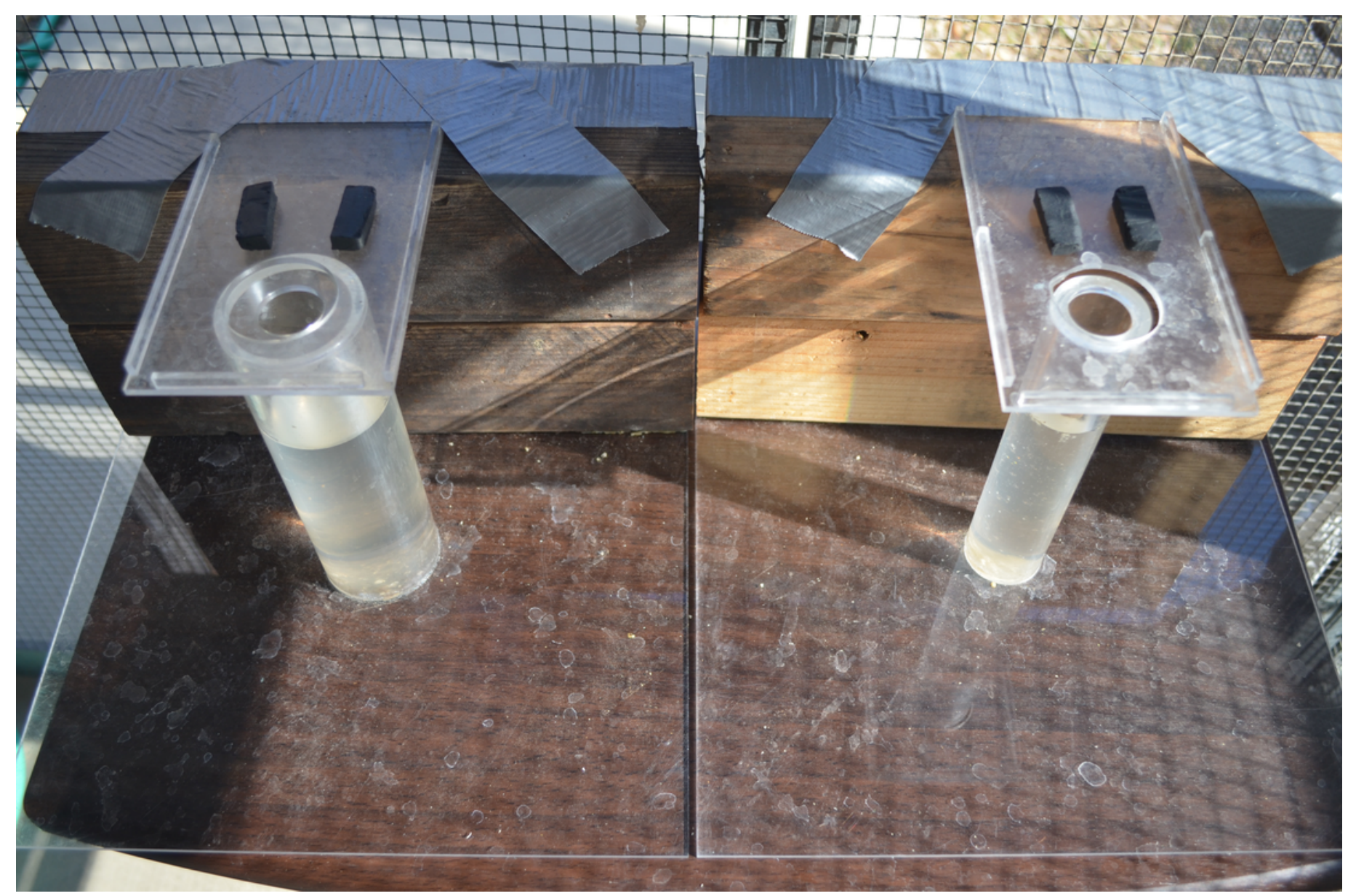




\section{Table $\mathbf{1}$ (on next page)}

Color association results

The number of trials needed to reach proficiency in Experiment 1 (learning speed), and Experiment 2 (reversal learning speed), and the number of trials needed to pass the Experiment 1 refresher $(*=$ did not pass the refresher in 10 trials). 
1 Table 1. Color association results: The number of trials needed to reach proficiency in 2 Experiment 1 (learning speed), and Experiment 2 (reversal learning speed), and the number of 3 trials needed to pass the Experiment 1 refresher ( $*=$ did not pass the refresher in 10 trials).

\begin{tabular}{lllll}
\hline Bird & Sex & $\begin{array}{l}\text { Experiment 1: } \\
\text { Learning speed }\end{array}$ & $\begin{array}{l}\text { Experiment 2: } \\
\text { Reversal } \\
\text { learning speed }\end{array}$ & $\begin{array}{l}\text { Experiment } \\
\text { 1 refresher }\end{array}$ \\
\hline Tequila & $\mathrm{M}$ & 30 & $100^{*}$ & 30 \\
Margarita & $\mathrm{F}$ & 30 & 100 & 10 \\
Cerveza & $\mathrm{F}$ & 30 & 90 & 10 \\
Michelada & $\mathrm{F}$ & 40 & 70 & 10 \\
Horchata & $\mathrm{F}$ & 30 & $130^{*}$ & 50 \\
Refresco & $\mathrm{M}$ & 20 & $70^{*}$ & 80 \\
Batido & $\mathrm{M}$ & 30 & Incomplete* & 30 \\
Jugo & $\mathrm{M}$ & 40 & 80 & 10 \\
\hline
\end{tabular}

4

5 


\section{Table 2 (on next page)}

Performance per bird in the water tube experiments (3-6)

The number of stone dropping training trials needed to reach proficiency, and p-values from Bonferroni-Holm corrected (within experiment) binomial tests for each experiment (- = was not given this experiment). Note: Tequila was the first bird tested and I did not realise until after I trained him to pick up and drop the stones into the tube that I wanted to only train the other birds to push the stones into the tube to save training time. Therefore, the trial numbers for the other birds refer to proficiency to push objects into the tube, not pick up and drop them. $\mathrm{Y}=$ yellow, $\mathrm{P}=$ purple, $\mathrm{B}=$ blue, $\mathrm{O}=$ orange, $\mathrm{R}=$ red, $\mathrm{G}=$ green. 
1 Table 2. Performance per bird per experiment: the number of stone dropping training trials

2 needed to reach proficiency, and the number of (more) functional choices/total number of

3 choices and p-values from Bonferroni-Holm corrected (within experiment) binomial tests for

4 each experiment (- = was not given this experiment). Note: Tequila was the first bird tested and I

5 did not realise until after I trained him to pick up and drop the stones into the tube that I wanted

6 to only train the other birds to push the stones into the tube to save training time. Therefore, the

7 trial numbers for the other birds refer to proficiency to push objects into the tube, not pick up and

8 drop them. $\mathrm{Y}=$ yellow, $\mathrm{P}=$ purple, $\mathrm{B}=$ blue, $\mathrm{O}=$ orange, $\mathrm{R}=$ red, $\mathrm{G}=$ green.

\begin{tabular}{|c|c|c|c|c|c|}
\hline Bird (color rings) & Sex & $\begin{array}{l}\text { Stone drop } \\
\text { training trials }\end{array}$ & Heavy vs. Light & $\begin{array}{l}\text { Heavy vs. Light } \\
\text { Magic }\end{array}$ & $\begin{array}{l}\text { Wide vs. } \\
\text { Narrow Equal }\end{array}$ \\
\hline Tequila (YP) & M & 192 push / 233 drop & $\begin{array}{l}33 / 43 \\
0.003 \text { (heavy) }\end{array}$ & $\begin{array}{l}19 / 30 \\
0.60\end{array}$ & - \\
\hline Margarita (PB) & $\mathrm{F}$ & 362 & $\begin{array}{l}41 / 49 \\
0.00001 \text { (heavy) }\end{array}$ & $\begin{array}{l}17 / 56 \\
0.02 \text { (heavy) }\end{array}$ & - \\
\hline Cerveza (BO) & $\mathrm{F}$ & 252 & $\begin{array}{l}36 / 55 \\
0.06\end{array}$ & $\begin{array}{l}10 / 39 \\
0.02 \text { (heavy) }\end{array}$ & 1.00 \\
\hline Michelada (OR) & $\mathrm{F}$ & - & - & - & - \\
\hline Batido (OP) & M & 179 & $\begin{array}{l}38 / 51 \\
0.002 \text { (heavy) }\end{array}$ & $\begin{array}{l}28 / 37 \\
0.02 \text { (heavy) }\end{array}$ & 1.00 \\
\hline Horchata (GR) & $\mathrm{F}$ & 135 & $\begin{array}{l}18 / 32 \\
0.60\end{array}$ & $\begin{array}{l}16 / 32 \\
1.00\end{array}$ & - \\
\hline Refresco (PY) & M & 204 & $\begin{array}{l}46 / 67 \\
0.009 \text { (heavy) }\end{array}$ & $\begin{array}{l}17 / 35 \\
1.00\end{array}$ & 1.00 \\
\hline Jugo (RB) & M & - & - & - & - \\
\hline
\end{tabular}




\section{Table 3(on next page)}

Examining test performance and learning effects in the water tube experiments (3-6)

Examining the influence of experiment, trial, and bird on test success (Test Performance) and whether success increased with trial number (Learning Effects), thus indicating a learning effect. GLMM: Choices Correct $\sim$ Experiment*Trial*Bird, random $=\sim$ Choice Number. $\mathrm{Cl}=$ credible intervals, Batido in italics indicates the intercept. 
1 Table 3. Examining the influence of experiment, trial, and bird on test success (Test

2 Performance) and whether success increased with trial number (Learning Effects), thus

3 indicating a learning effect. GLMM: Choices Correct $\sim$ Experiment*Trial*Bird, random =

$4 \sim$ Choice Number. $\mathrm{CI}=$ credible intervals, Batido in italics indicates the intercept.

\begin{tabular}{|c|c|c|c|c|c|c|}
\hline & \multicolumn{3}{|c|}{ Test Performance } & \multicolumn{3}{|c|}{ Learning Effects } \\
\hline & $\begin{array}{l}\text { Posterior } \\
\text { Mean }\end{array}$ & $\begin{array}{l}\text { Lower } \\
95 \% \text { CI }\end{array}$ & $\begin{array}{l}\text { Upper } \\
95 \% \text { CI }\end{array}$ & $\begin{array}{l}\text { Posterior } \\
\text { Mean }\end{array}$ & $\begin{array}{l}\text { Lower } \\
95 \% \text { CI }\end{array}$ & $\begin{array}{l}\text { Upper } \\
95 \% \text { CI }\end{array}$ \\
\hline Choice number & 0.002 & $1.39 \mathrm{E}-16$ & 0.002 & - & - & - \\
\hline \multicolumn{7}{|l|}{ Heavy vs. Light } \\
\hline Batido & 1.36 & -0.03 & 2.83 & -0.01 & -0.13 & 0.12 \\
\hline Margarita & 0.29 & -2.31 & 2.83 & 0.04 & -0.17 & 0.26 \\
\hline Cerveza & -1.92 & -4.06 & 0.10 & 0.13 & 0.05 & 0.32 \\
\hline Horchata & -1.01 & -3.14 & 1.14 & 0.01 & -0.20 & 0.19 \\
\hline Refresco & -0.13 & -2.07 & 2.13 & -0.01 & -0.19 & 0.16 \\
\hline Tequila & 0.22 & -1.96 & 2.47 & -0.003 & -0.20 & 0.22 \\
\hline \multicolumn{7}{|c|}{ Heavy vs. Light Magic } \\
\hline Batido & -2.11 & -4.66 & -0.11 & -0.06 & -0.25 & 0.16 \\
\hline Margarita & -0.20 & -3.63 & 3.14 & -0.01 & -0.32 & 0.28 \\
\hline Cerveza & 2.13 & -1.33 & 4.86 & -0.18 & -0.45 & 0.15 \\
\hline Horchata & 2.60 & -0.83 & 5.87 & -0.03 & -0.31 & 0.28 \\
\hline Refresco & -1.32 & -4.73 & 1.92 & 0.33 & 0.03 & 0.62 \\
\hline Tequila & -1.05 & -4.50 & 2.43 & 0.17 & -0.17 & 0.50 \\
\hline \multicolumn{7}{|l|}{ Narrow vs. Wide } \\
\hline Batido & -1.12 & -3.10 & 0.88 & 0.01 & -0.15 & 0.19 \\
\hline Cerveza & -0.21 & -3.61 & 2.74 & 0.06 & -0.20 & 0.33 \\
\hline Refresco & -0.48 & -3.49 & 2.77 & 0.02 & -0.23 & 0.25 \\
\hline
\end{tabular}




\section{Table 4 (on next page)}

Summary of results

The learning strategy or strategies employed by each bird as well as the number of trials to reach proficiency in Experiment 1, the number of trials needed to reverse their preference (Experiment 2) minus the number of trials needed to initially learn the preference (Experiment 1; a measure of behavioral flexibility), and whether they exhibited a preference change between Experiments 3 and 4. -=preferred to stick heavy objects to the magnet thus the experiment did not test what it was designed to test in these individuals, $X=$ did not participate in this experiment. 
1 Table 4. Summary of results: The learning strategy or strategies employed by each bird as well 2 as the number of trials to reach proficiency in Experiment 1, the number of trials needed to 3 reverse their preference (Experiment 2) minus the number of trials needed to initially learn the 4 preference (Experiment 1; a measure of behavioral flexibility), and whether they exhibited a 5 preference change between Experiments 3 and 4. (No)=preferred to stick heavy objects to the 6 magnet thus the experiment did not test what it was designed to test in these individuals however 7 they were included in the Spearman's rank test to increase the sample size, $X=$ did not participate 8 in this experiment.

\begin{tabular}{|c|c|c|c|c|c|}
\hline Bird & Sex & $\begin{array}{l}\text { Learning } \\
\text { strategy }\end{array}$ & $\begin{array}{l}\text { Experiment 1: } \\
\text { Learning speed }\end{array}$ & $\begin{array}{l}\text { Behavioral flexibility } \\
\text { (Exp } 2 \text { - Exp 1) }\end{array}$ & $\begin{array}{l}\text { Behavioral } \\
\text { flexibility } \\
\text { (water tube) }\end{array}$ \\
\hline Tequila & $\mathrm{M}$ & $\begin{array}{l}\text { Epsilon- } \\
\text { decreasing }\end{array}$ & 30 & 70 & Yes \\
\hline Margarita & $\mathrm{F}$ & $\begin{array}{l}\text { Epsilon- } \\
\text { decreasing }\end{array}$ & 30 & 70 & (No) \\
\hline Cerveza & $\mathrm{F}$ & $\begin{array}{l}\text { Epsilon- } \\
\text { decreasing }\end{array}$ & 30 & 60 & (No) \\
\hline Horchata & $\mathrm{F}$ & $\begin{array}{l}\text { Epsilon- } \\
\text { decreasing }\end{array}$ & 30 & 100 & No \\
\hline Refresco & M & $\begin{array}{l}\text { Epsilon-first, then } \\
\text { epsilon-decreasing }\end{array}$ & 20 & 50 & Yes \\
\hline Batido & M & $\begin{array}{l}\text { Epsilon- } \\
\text { decreasing }\end{array}$ & 30 & - & No \\
\hline Michelada & $\mathrm{F}$ & $\begin{array}{l}\text { Epsilon- } \\
\text { decreasing }\end{array}$ & 40 & 30 & $\mathrm{X}$ \\
\hline Jugo & M & $\begin{array}{l}\text { Epsilon- } \\
\text { decreasing }\end{array}$ & 40 & 40 & $\mathrm{X}$ \\
\hline
\end{tabular}

